OPEN ACCESS

Edited by:

Medhat Elkelawy,

Tanta University, Egypt

Reviewed by:

Muthu Manokar A.,

B. S. Abdur Rahman Crescent Institute Of Science And Technology,

India

Kishan Pal Singh,

Mangalayatan University, India

${ }^{*}$ Correspondence:

Naeem Abas

naeemkalair@uog.edu.pk

Specialty section:

This article was submitted to

Sustainable Energy Systems and Policies,

a section of the journal

Frontiers in Energy Research

Received: 24 February 2021

Accepted: 18 June 2021

Published: 22 July 2021

Citation:

Kalair AR, Dilshad S, Abas N, Seyedmahmoudian M, Stojcevski A and Koh K (2021) Application of Business Model Canvas for Solar

Thermal Air Conditioners.

Front. Energy Res. 9:671973. doi: 10.3389/fenrg.2021.671973

\section{Application of Business Model Canvas for Solar Thermal Air Conditioners}

\author{
Ali Raza Kalair ${ }^{1}$, Saad Dilshad ${ }^{2}$, Naeem Abas ${ }^{3 \star}$, Mehdi Seyedmahmoudian $^{1}$, Alex Stojcevski ${ }^{1}$ \\ and Kek Koh ${ }^{4}$
}

${ }^{1}$ Department of Telecommunications, Electrical, Robotics and Biomedical Engineering, Swinburne University, Hawthorn, VIC, Australia, ${ }^{2}$ Department of Electrical and Computer Engineering, COMSATS University Islamabad, Islamabad, Pakistan,

${ }^{3}$ Department of Electrical Engineering, University of Gujrat, Gujrat, Pakistan, ${ }^{4}$ Brightcell energy, Melbourne, VIC, Australia

Growing populations, burgeoning economies, and technology-driven lifestyles demand an increasing supply of energy. The existing energy supply pattern primarily depends on fossil fuels that have initiated climate change-provoking myriad problems. Integration of renewable energy sources in the existing energy supply system is a complex and challenging task keeping in view the depleting fossil fuels and prevailing environmental challenges. The existing cold storage farms are working on traditional compressors and the HVAC system, causing more use of electricity. Similarly, existing data centers and supermarkets are also using conventional refrigerants. These systems also use hazardous environmental refrigerants, which make these systems more dangerous. In the summer season, comfort cooling and refrigeration requirements rise to peak in hot climate areas forcing utilities to supply more electrical energy to meet the demand. Therefore, a solar thermal cooling system employing a solar absorption chiller operated through a hot water stream generated by a solar evacuated glass tube collector with $\mathrm{CO}_{2}$ as a refrigerant is simulated in the TRNSYS ${ }^{\circledR}$ simulation environment. The results are generated for the hot climate of Multan, Pakistan, and the average obtained temperatures of the three rooms, cold storage, office, and kitchen room, were $18.43,26.25$, and $29.83^{\circ} \mathrm{C}$, respectively. However, every startup or new idea needs a proper business model before entering into the market. This article offers a complete insight and a future perspective for the reader to develop a precise business model for the commercialization of his or her project. A business model is designed for solar thermal air conditioners for domestic, cold storage, and data centers applications in the world, after reviewing and interviewing manufacturers and customer segment in air conditioning fields. Data were collected through semistructured one-to-one interviews from a convenient sample of 10 national and international respondents, and their views were thematically analyzed. The implementation of a business model using a case for the Pakistani market is

\footnotetext{
Abbreviations: AEDB, Alternative Energy Development Board; BMC, Business Model Canvas; BP, British Petroleum; CDD, Cooling Degree Days; CFC, Chlorofluorocarbons; COP, Coefficient of Performance; CTC, Carbon tetrachlorideEGTC, Evacuated Glass Tube Collector, ESC Energy Service Company; ESRL, Earth System Research Laboratory; GHGs, Greenhouse gas; GWP, Global warming potential; HC, Hydro Carbons; HCFC, Hydrochlorofluorocarbons; HFC, Hydrofluorocarbons; IEA, International Energy Agency; MVP, Minimum Viable Product; Natrefs, Natural refrigerants; NPV, Net Present Value; ODP, Ozone Depletion Potential; ODs, Ozone Depleting Substances; ORC, Organic Rankine Cycle; PCRET, Pakistan Council of Renewable Energy Technologies; PV, Photovoltaic; RE, Renewable Energy; SHCS, Solar Heating and Cooling System; STC, Story Telling Canvas; TR, Tons of Refrigeration; UV, Ultra violet.
} 
presented. A business model for a solar cooling system utilizing abundant $\mathrm{CO}_{2}$ as a refrigerant is presented in this article. This business model is equally suitable for designing a business model for any renewable energy product in the world.

Keywords: renewable energy, solar cooling, business mode, startup, business model canvas, refrigeration

\section{INTRODUCTION}

The world energy demands are rising substantially due to an increase in population, economic growth, and the heating and air conditioning markets in the domestic and commercial sectors. The latest report by the International Energy Agency (IEA) investigated that the energy demand grew by $0.9 \%$ in 2019 (IEA, 2020). Nevertheless, the global energy demand declined by $3.8 \%$ in the first quarter of 2020 and was expected to fall by $5 \%$ in 2020 due to the COVID-19 pandemic and its subsequent lockdowns (World Energy Outlook 2020-Analysis-IEA, 2020). However, the increase in demand was 2.3 and $2.1 \%$ in 2018 and 2017, respectively (IEA, 2019). Owing to an increase in consumption, the $\mathrm{CO}_{2}$ emissions raised $1.7 \%$ in 2018 and touched the high of $33.1 \mathrm{Gt} \mathrm{CO}_{2}$. This increase is mostly due to an increase in all fossil fuel use, and nearly two-thirds of these emissions are only from the power sector (IEA, 2019). The growing consumption of fossil fuels leads to environmental problems such as global warming, climate change, and ozone depletion. According to the Earth System Research Laboratory (ESRL) on March 9, 2020, the daily average of $\mathrm{CO}_{2}$ at Mauna Loa has reached up to $413.95 \mathrm{ppm}$ (Tans, 2020). The increasing $\mathrm{CO}_{2}$ emissions account for around $78 \%$ of the total greenhouse gas (GHG) emissions raise from 1970 to 2010 in the world (Edenhofer et al., 2014). Therefore, it is considered a significant threat to the Earth's atmosphere. The extreme utilization of coal and oil is regarded as the primary source for $\mathrm{CO}_{2}$, and emissions of other toxic gases are responsible for global warming (Abas and Khan, 2014; Khan et al., 2019). Moreover, questions about the limitation of fossil fuel reserves are also being raised (Abas et al., 2015). The world has determined to limit the average increase in global temperature to less than $2^{\circ} \mathrm{C}$ by the end of this century (United Nations, 2015; Gao et al., 2017). Now, it is a significant challenge to match the global energy demand to sustain industrialization and fulfill energy needs, simultaneously reducing environmental degradation (Hussain et al., 2019).

The negative impact of burning fossil fuels has forced researchers to consider renewable energy (RE) technologies (Basit et al., 2020) to reduce the growing $\mathrm{CO}_{2}$ emissions. Integration of RE sources in the existing energy supply system is a complex and challenging task keeping in view the depleting fossil fuels and prevailing environmental challenges. However, capturing $\mathrm{CO}_{2}$ and utilizing it for the purpose of cooling and refrigeration assisted by solar energy can lower these emissions. $\mathrm{CO}_{2}$ is already being used as a refrigerant in the world; the European and Japanese markets are leading, with operational $\mathrm{CO}_{2}$ transcritical stores reaching up to $16,000+$ and $3,530+$, respectively. The transcritical $\mathrm{CO}_{2}$ installations in other regions have a growing trend such as North and South America (635+), South Africa (110), Australia (20), and
New Zealand (41) (Dilshad et al., 2020). Solar energy stands as the first choice of RE by the virtue of its availability and climate-friendly nature. With the best use of refrigeration technology, solar cooling can help mitigate these problems. The authors have already demonstrated a solar water heater using $\mathrm{CO}_{2}$ as a refrigerant (Abas et al., 2014; 2017; 2019a) and received a patent on a gravity-driven $\mathrm{CO}_{2}$-based thermosiphon solar water heater for cold regions in the world (Abas et al., 2019b). The application of solar energy for refrigeration along with $\mathrm{CO}_{2}$ as a refrigerant can advantageous for the Earth's climate. The conjunction of cooling demand peaks with warm weather bargains an exceptional opportunity to employ solar thermal energy in refrigeration and air conditioning (Balaras et al., 2006). Hence, there is a need for low power, solar cooling, refrigeration technology to improve the living standards of people on the earth.

Researchers/engineers working in different technical fields are producing innovative ideas and doing their research with the help of funding agencies. But, unfortunately after the completion of creative design the product did not go into the market for commercialization because of several factors, e.g., lack of business or start-up knowledge, no or little collaboration with industries, and working on only own research interest without knowing the market needs. Owing to these reasons, many products are wasted after spending plenty of money on its development. Hence, the successful start-up, commercialization, and marketing of the product are necessary for the tireless efforts of the researchers. However, a researcher cannot hire a marketing team initially for his product development and marketing. Furthermore, the marketing team alone cannot adequately suggest ideas for product development. Hence, a creator has to go out to the customers to take some interviews regarding his developed hypothesis. Van Norman and Eisenkot (2017) have presented a way for technology transfer, starting from the acquisition of intellectual property rights (patent and copyrights) to the licensing of startup companies or directly into the industry and process of commercialization. This research is helpful for researchers working on innovative projects to get knowledge about basic rules and regulation for the commercialization of their research projects.

In literature, various researchers have proposed different types of techniques to develop business model strategies such as relating to business ecologies of business models (Bocken et al., 2019), risk analysis of the sustainable business model in the energy sector (Leisen et al., 2019), integration of Business Model Canvas (BMC) and technology road map (Toro-Jarrín et al., 2016), and business model challenges for a solar company in Germany (Karakaya et al., 2014; 2016). Various researchers have also proposed innovative business model ideas such as the business model for a solar heat pump water heater ( $\mathrm{Li} \mathrm{Z}$. 
et al., 2019), distributed photovoltaic (PV) energy in China (Zhang, 2016), a PV water pumping system in China (Zhang and Yan, 2014), accelerating renewable electrification and rural economic development (Li and Shen, 2019), and battery storage (Li X. et al., 2019). Few business model strategies are discussed later.

Li et al. have presented a multi-energy cooperative utilizationbased business model for the solar heat pump water heaters focusing on the market in China. Their research involves the business model creation based on Net Present Value (NPV) method, payback period method, and Internal Rate Of Return (IRR) method. Three assumptions were made for the business of solar heat pump water heater; i) no third-pay model, ii) government intervention model, and iii) Energy Service Company (ESCO) intervention based (Li Z. et al., 2019). The outcomes of these business models describe that the business model for hot water heaters is less competitive with no thirdparty model. A proper subsidy is to be provided by the government to attract people to buy this product, and this can help in reducing the electricity demand and its prices in the future. However, this subsidy will be an immense burden on the government. The ESCO intervention model can help the consumer in buying such a product with low risk. However, the return rate for ESCO organizations is weak. An improved business model for better incentives for all stakeholders can be achieved by involving both the ESCO and the government. These models can be adopted for various RE projects for its commercial availability in the market. However, the governments in the developing countries cannot offer much subsidies for innovative projects due to the economic barriers and political influence.

Bocken et al. (2019) have presented a sustainable business model by using different ecologies of business models. Two companies such as THANKS and HOMIE were taken as tests and ecology of business models experimentation maps were made for these companies. However, their business model design was majorly more focused on business, organizations, and firm structure and therefore cannot be adopted for an innovative project and its commercialization.

A BMC identifies the vital elements of the business and Technology Roadmap is used to envisage the linkage over time of market and technology and product strategies. The primary benefit of Technology Roadmap is the identification of gaps among the present and future business tactics. Toro-Jarrín et al. (2016) have presented a business process integration model of these two tools to give an idea about a BMC and Technology Roadmap for a business idea or startup, which are allied for present and future needs.

Most of these business models are either for RE projects (Zhang, 2016) (Li and Shen, 2019), solar PV systems (Zhang, 2016), solar PV water pumping systems (Zhang and Yan, 2014), or solar heat pumps (Li Z. et al., 2019). However, these models are either PV based and have chlorofluorocarbons (CFCs) and hydrochlorofluorocarbons (HCFCs)-based heat pump systems. Therefore, a business model for solar thermal cooling using $\mathrm{CO}_{2}$ as a refrigerant is developed and presented in this article. This business model helps to develop a proper knowledge design to the researchers in developing a business model design for the start-up and commercialization of their project. The business model used as a framework for analysis and design in this article is adapted from Osterwalder and Pigneur (2010), Osterwalder et al. (2014). This design allows an owner to build his initial BMC. Then, after conducting several interviews and surveys in markets, he or she can analyze his or her initial BMC and gather knowledge from interviews. Thus, only the Minimum Viable Product (MVP) is made at startup, and the business model is improved and updated through customer discovery interviews. The thing to remember is that the new BMC is also not final as there always exists an opportunity to grow in the markets, and any competent contender can come up with the same idea in the market. Therefore, some possible pivots should be considered in mind and their solutions, which can be readily applicable. The design criteria also help to further improve the product in a better shape by introducing more features that are already defined in MVP. In the last section of MVP, properties are also discussed by using ten key principles for solar thermal cooling applications. These ten fundamental principles were defined by Neyer et al. (2018) for summarizing the features of the IEA Solar Heating and Cooling System (SHCS) project task 48.

The rest of this article is organized as: Materials and Methods describes the proposed research method and a comprehensive review about the significance of solar thermal cooling technologies. Results covers the development of a business model by applying a Value Proposition Canvas (VPC), BMC, design criteria for MVP, and after conducting interviews, a new BMC is developed. Business Model for Solar Thermal Cooling in Pakistan includes the implementation of the business model using a case for the Pakistani market and the scope of implementing such projects in Pakistan. The brief concluding remarks and future perspectives of this research are presented in Conclusion and Future Prospects.

\section{MATERIALS AND METHODS \\ Review of Solar Thermal Cooling Technologies}

The solar air conditioning system has typically three subsystems: the solar energy harvesting system, refrigeration system, and the air conditioning load. The suitable approach for each application depends on the factors such as cooling demand, energy source, and temperature levels. First, considering the solar energy conversion system to capture the solar energy, there are two important paths to follow: thermal collectors for thermal energy or PV cells for electricity. A standard PV system available in the market can harvest $46 \%$ visible light energy and gives the efficiency of below 30\%. However, the solar thermal systems can harvest $98 \%$ visible light and heat energies, and they provide the efficiency of $60-70 \%$. Although the efficiency of systems driven by electricity is relatively high, the cost of PV panels and batteries is also very high, and conversion efficiency of the PV system is very low. This makes it a relatively expensive and less efficient approach. On the other hand, heat-driven cycles are less efficient, but the conversation efficiency of thermal collectors is much higher than that of PV collectors. 
The most significant possible methods from solar energy to air conditioning services are presented in Figure 1. After the selection of the way to harvest solar energy, the important phase is the selection of the cooling cycle. Different types of thermal collectors can correspond to different cycles depending on their temperature levels. For example, the comfort cooling and air conditioning application can be operated through a vapor compression cycle using the PV panel, and any other cycle can be used for this because the temperature requirement is not very low. On the other side, the Rankine cycle needs a rather hightemperature level from the collectors. The possible solar heatdriven cycles are absorption, adsorption, Rankine and ejector cycle, etc.

The promising application for solar thermal cooling is an absorption cooling system as it accounts for around $70 \%$ of the total installed solar cooling systems in the world. The remaining cooling systems are solid desiccant, adsorption, liquid desiccant, and other approaches have a share of $14,13,2$, and $1 \%$ respectively (Baniyounes et al., 2013). In this absorption cooling, the compressor of a conventional vapor compression cycle is replaced by a heat pump and an absorber. The essential advantages of the absorption cooling are that it can provide the higher coefficient of performance (COP) as contrasted to other thermally operated cooling methods, low noise, and more life span. The $\mathrm{H}_{2} \mathrm{O} / \mathrm{LiBr}$ is widely used as the working fluid due to their environment-friendly and nontoxic nature as compared with the ammonia-based system.

A considerable amount of research work is done on absorption refrigeration, and this technology is entirely mature and available in the market for large-scale applications. Currently, in commercial refrigeration, it is not easy to decide on the ultimate choice of refrigerants and system type. In the last decade, many refrigerants options and system designs have appeared in both papers and practice. The air conditioning and refrigeration field are in the environmental spotlight in recent years because of high ODP-based CFCs and HFCs. Hence, the choice of suitable refrigerants and design is still a valuable interest for researchers and the market.

In the literature, the researchers have proposed various methods for solar-based cooling systems, but only a few systems have been installed. The attraction of solar cooling is due to the reason that its requirement is most substantial when solar energy is abundantly available. There are three most promising cooling approaches: the Absorption cooling, Rankine cycle heat engine coupled with cooling loop, and desiccant systems. Before discussing on how solar energy could provide refrigeration, it is essential to describe that the basic principle of solar-based refrigeration is based on vapor compression cycles; vapor compression cycle forms the basis of almost all conventional cooling systems. In an absorption cooling cycle, an absorber and a generator are installed instead of a compressor. It works on the natural properties of chemicals to dissolve in each other at one temperature and leave each other when heated by some source. The two fluid combinations that are mostly used in this process are lithium bromide and water $\left(\mathrm{H}_{2} \mathrm{O} /\right.$ $\mathrm{LiBr}$ ) and ammonia and water $\left(\mathrm{NH}_{3} / \mathrm{H}_{2} \mathrm{O}\right)$ (Jakob et al., 2008; Pongtornkulpanich et al., 2008; Agyenim et al., 2010; Praene et al., 2011). The high-pressure gases leave upon heating and pass the condenser and expansion valve as a refrigerant to produce the cooling effect in the evaporator. This is how the absorption cooling cycle operates. The absorption cooling systems are further divided into three types on the working of their operation: single-effect, double-effect, and half-effect absorption cooling systems.

The different solar-based system having $\mathrm{H}_{2} \mathrm{O} / \mathrm{LiBr}$ as a mediating fluid has been installed and tested by Tierney (2007) and Darkwa et al. (2012). The drawback of using a $\mathrm{H}_{2} \mathrm{O} / \mathrm{LiBr}$ mediating fluid pair is its incapability to operate at

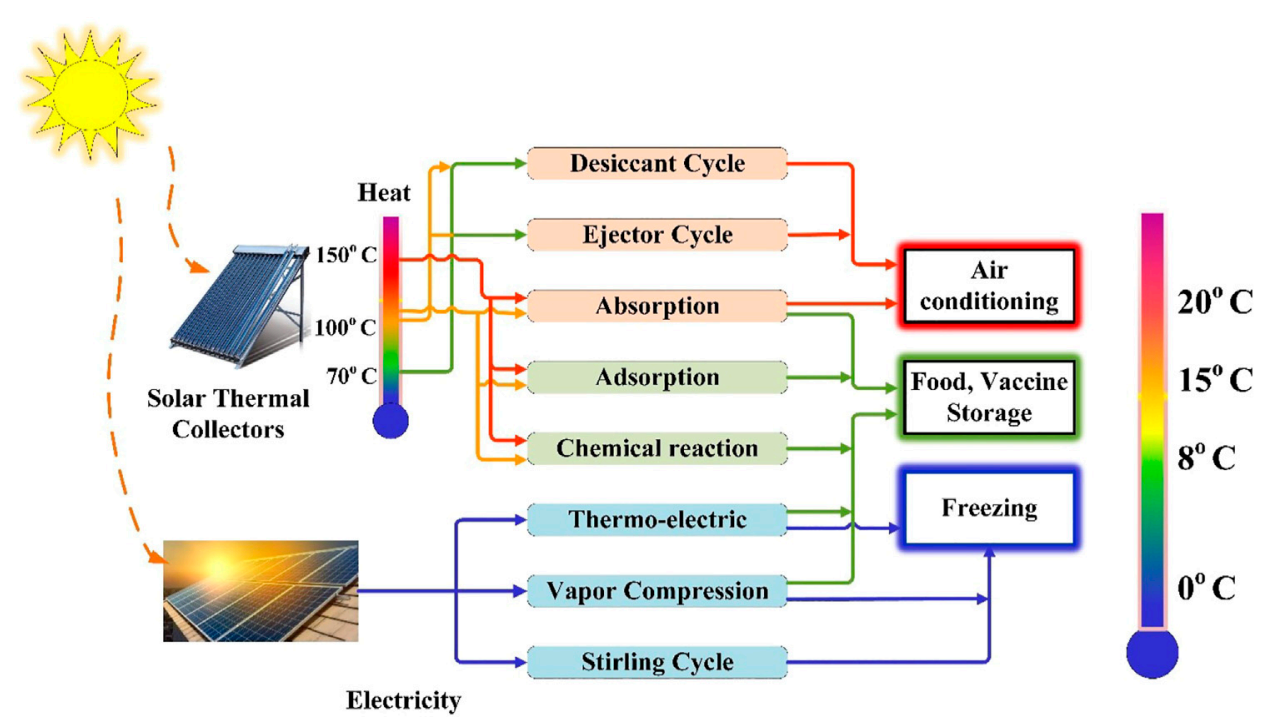

FIGURE 1 | Solar cooling/refrigeration methods. 
a condensation temperature higher than $40^{\circ} \mathrm{C}$ owing to crystallization and at below $0^{\circ} \mathrm{C}$ due to the freezing of the mediating fluid water (Izquierdo et al., 2004). The solution to these limitations is presented in the form of a $\mathrm{NH}_{3} / \mathrm{H}_{2} \mathrm{O}$ pair as a mediating fluid (Hassan and Mohamad, 2012a). Many test systems and research projects have been developed by researchers using $\mathrm{NH}_{3} / \mathrm{H}_{2} \mathrm{O}$ (Hassan and Mohamad, 2012b; Boudéhenn et al., 2012). The toxicity and volatile nature of ammonia are the significant drawback of the ammonia-based system, in which toxicity leads to safety concerns and volatile nature affects the overall efficiency of the system (Park and Sonntag, 1990; Patek and Klomfar, 1995).

The second approach of the Rankine cycle heat engine coupled with a cooling loop is still in the development process. A typical Rankine cycle heat engine-based solar air conditioning system is presented in Figure 2. It consists of three loops, heat energy is absorbed from the Sun and delivered to the Rankine cycle through a heat exchanger, the steam or $\mathrm{CO}_{2}$ can serve as a mediating fluid in the Rankine loop. The Rankine turbine is directly attached to operate the compressor motor. The $\mathrm{CO}_{2}$ is used as a refrigerant in the cooling cycle. Nowadays, $\mathrm{CO}_{2}$ is widely evaluated in the Rankine cycle system by various researchers (Yamaguchi et al., 2006; Zhang et al., 2007; Niu et al., 2011; Sarkar, 2015). A system is proposed with a combination of Organic Rankine Cycle (ORC) integrated with the heliostat field and a central receiver (Khaliq, 2017). The results depict that by increasing the expander inlet pressure and evaporator temperature, the energy and energy efficiency of the integrated system can be improved. Different researchers have proposed solar power Rankine cycle using $\mathrm{CO}_{2}$ as the working fluid (Yamaguchi et al., 2006; Zhang et al., 2007). There are two types of heat engines; one type has the mediating fluid that cyclically changes the phase from liquid to gas and back to liquid, the second one has a mediating fluid that remains in a gaseous state. The examples are the Rankine cycle and Stirling and Bryton cycles, respectively.

The third approach for converting solar energy into cooling is a desiccant cooling. The absorption cooling system is closed cycles and has a fixed amount of mediating fluid circulating within the sealed pipes. But the desiccant cooling system is open cycles loop systems. Since working fluid involves air and water. The working principle of desiccant cooling is to dehumidify air with desiccant wheel, and evaporatively cool the dehumidified air and regulate the desiccant with solar powered energy. A liquid desiccant based solar air conditioning systems are proposed by Mehta and Rane (2013). The system uses the aqueous Potassium Format solution. The solar thermal cooling technologies are mostly available in the market with above $40 \mathrm{~kW}$ capacities. However, small units are not available for commercial or residential is still in the $R \& D$ stage.

In other solar thermal-based cooling technologies, Huang et al. (2010) have presented control of the solar-assisted cooling system using the ejector cycle. In this work, three loops were developed-a solar circuit, ejector-based cooling loop, and an inverter-based heat pump loop. During the sunlight, the cooling is done by the ejector cooling cycle and the compressor on the other side is not used; during clouds, the system receives cooling requirement from inverters-based cooling. Hence, these two systems are combined with working together based on the solar radiation intensity and evaporator temperature settings (Huang et al., 2010).

\section{Review of Protocols and Accords for the Protection of Ozone}

The CFCs and HCFCs were widely being used in cooling applications due to their better performance as refrigerants. In 1973, it was found that these CFCs and HCFCs are responsible for the decomposition of the ozone layer (Molina and Rowland, 1974; Stolarski and Cicerone, 1974). The world is also facing problems such as Global warming popularly referred to as Global Warming Potential (GWP) due to the increase in the consumption of coal, gas, and oil and the drastic effect of the halogenated refrigerants on the ozone layer. Ozone depletion is attributed to as Ozone Depletion Potential (ODP). The harmful impact of commonly used refrigerants has created worldwide concern over the use of such refrigerants. This concern leads to the phase-out of these refrigerants in recent years. Owing to these reasons the production of CFCs and HFCs was banned. In 1987 Montreal Protocol and in 1997 Kyoto Protocols recommended to

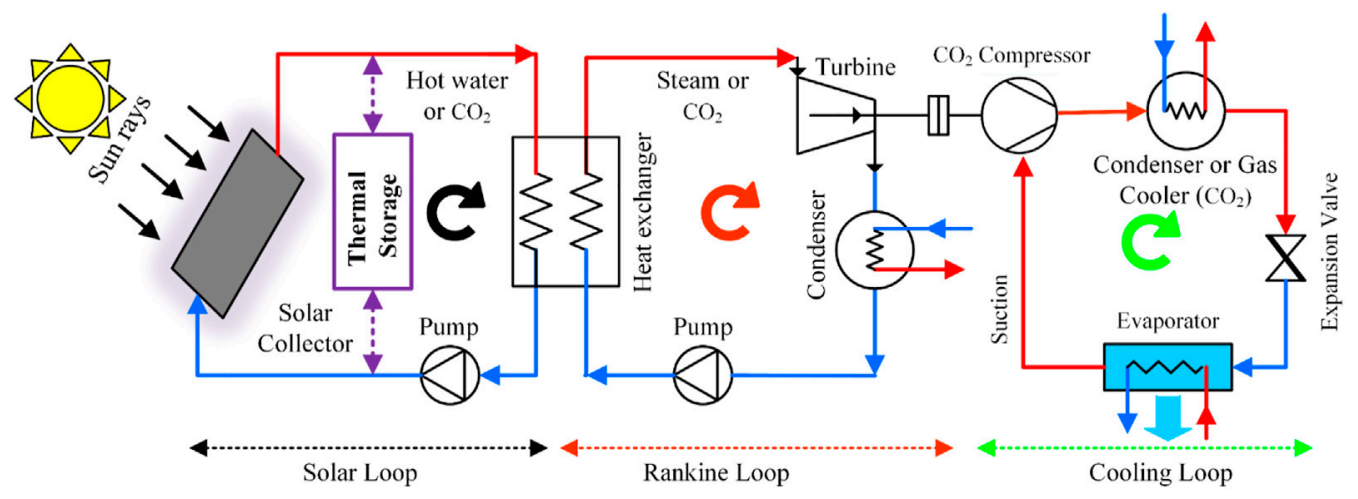

FIGURE 2 | Solar thermal cooling through Rankine cycle (Khan, 2006). 


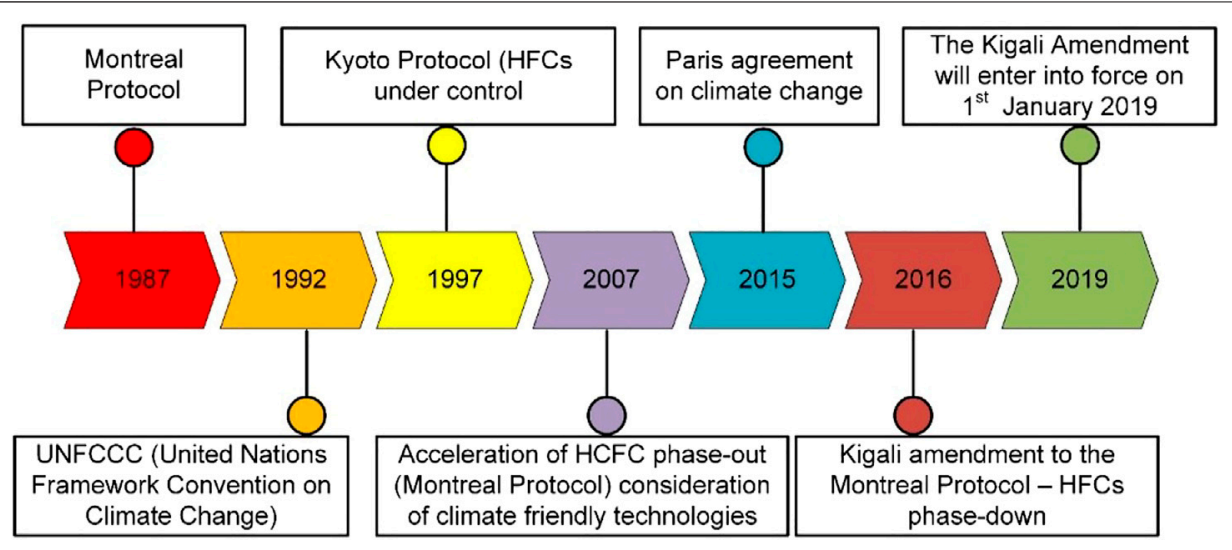

FIGURE 3 | A brief history of the protocols and accords for ozone depletion and climate change.

complete phase-out of HCFCs by 2015-2020 and HFC by 2030 (United Nations, 1997; 1998). Now this reason has given way to naturally occurring refrigerants to replace the CFCs and HFCs in refrigeration and heating system. A timeline of a brief history of the protocols and accords for ozone depletion and climate change is presented in Figure 3.

The ODP and GWP of HFC like R-410A are zero and 1,900, respectively. The HCFCs give OPD and GWP of 0.055 and 1,700 , respectively (Jia, 2009). In contrast, the $\mathrm{CO}_{2}$ in natural refrigerant only gives OPD and GWP of zero and one, respectively.

\section{Review of Refrigerants}

The air conditioning technology was started in ancient times when it comes to only passive cooling. The first successful attempt was made by Perkins in 1834 when he developed a hand-operated compressor with ether as refrigerant (Perkins, 1834). Then in 1851, Gorrie made an air refrigeration machine and, in 1856 Linde made a machine with ammonia as a refrigerant (Gorrie, 1851). In the beginning, the speed of development was slow because only steam engines were available to run the compressor at that time. A noteworthy advancement in refrigeration was the $\mathrm{NH}_{3},-\mathrm{H}_{2} \mathrm{O}$ absorption device by Ferdinand Carre in 1858 (Arora, 2012). This development accounts for major commercial and industrial applications in the field of refrigeration. The advent of electric motors has given a boost to air conditioning technology. A timeline of the brief history for the refrigerants is summarized and presented in Figure 4.

The era between 1830 and 1930s is considered the first generation of refrigerants. The commonly used refrigerants depending on which works best are $\mathrm{NH}_{3}, \mathrm{CO}_{2}, \mathrm{SO}_{2}, \mathrm{H}_{2} \mathrm{O}$, $\mathrm{CaCl}_{4}, \mathrm{HCOOCH}_{2}, \mathrm{HCs}, \mathrm{CHCs}$, etc. (Calm, 2008). A large portion of these refrigerants were poisonous, combustible, and exceptionally receptive and inclined to accidents (Calm, 2008; Abas et al., 2018). The air conditioning technology got a kick in the 1920s, with the invention of dichlorodifluorocarbon $\left(\mathrm{CCl}_{2} \mathrm{~F}_{2}\right)$

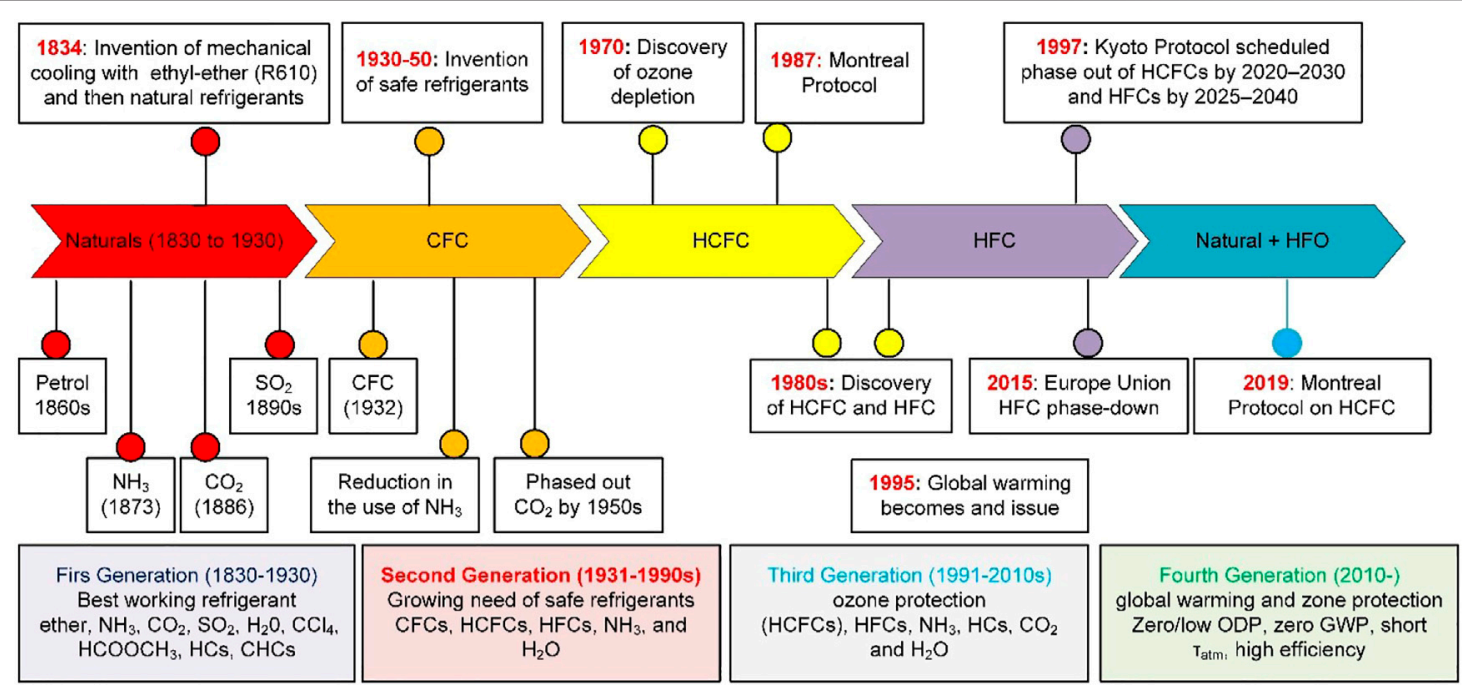

FIGURE 4 | A brief history of refrigerants used in cooling (Dilshad et al., 2020). 
in 1929 by Midgley and Henne (Halimic et al., 2003), which were commonly referred Freon-12 or CFC-12 refrigerants by Dupont de Nemours in 1932 (Benhadid-Dib and Benzaoui, 2012). CFCs have been utilized for quite a long time as refrigerants, solvents, as a blowing agent in the industry. New substances, the fluoro chloro derivatives of methane, ethane, etc., were invented and known as CFCs with another name of Freons. The second generation of refrigerants starts from 1931 to 1990s, constantly focused on the growing need for safe refrigerants.

The second generation refrigerants include CFCs, HCFCs, HFCs, $\mathrm{NH}_{3}$, and $\mathrm{H}_{2} \mathrm{O}$, etc. (Calm, 2008). In 1974, it was found that chlorine atoms present in Freons are majorly accountable for the depletion of the ozone layer in the atmosphere (Molina and Rowland, 1974; Stolarski and Cicerone, 1974). This shows an increasing trend in the ozone hole area from 1979 to 2000 . Hence, the Montreal Protocol (1987) was finalized to restrict the CFCs and consequently controlling the ozone hole area and ozonedepleting substances (United Nations, 1997). Meanwhile, HCFCs and hydrofluorocarbons (HFCs) were invented as a replacement for CFCs.

The third generation (1991-2010s), focusing on the ozone depletion, consists of low ODP HCFCs and HFCs, $\mathrm{NH}_{3}, \mathrm{H}_{2} \mathrm{O}$, $\mathrm{CO}_{2}, \mathrm{HCs}$, etc. However, due to the continuous increase in the ozone hole area, the HCFCs, and HFCs with high OPD and high GWP, a scheduled phase-out was suggested under the Kyoto Protocol (1997) (United Nations, 1998). Hence, a short-term permission to utilize HFCs is only an interim settlement, and after passing the due dates, the world should have better refrigerants with low ODP and no or little GWP. As we are approaching the deadlines, many countries of the world are reluctant to follow this-either authorities are unaware or having financial issues or less knowledge about this.
The post-2010 era is known as the fourth generation of refrigerants, with more focus on global warming and ozone protection. Therefore, refrigerants with zero ODP (R-32, R-134a, R-404a, R-410a, R-717, and R-744) are widely used. However, some of these refrigerants still have high GWP except some natural refrigerants (R-717 and R-744) (Raza Kalair et al., 2021). After the Paris agreement (2015) on climate change (United Nations, 2015) and the Kigali amendment to the Montreal protocol (2016) (Heath, 2017) to phase out of HCFCs, now, there is a need to find a suitable refrigerant having best refrigerate properties with no environmental impact. The first amendment of the Kigali Amendment to the Montreal protocol will enter into force on January 1, 2019.

\section{RESULTS}

\section{Simulation Results}

A solar absorption chiller operated through a hot water stream from Evacuated Glass Tube Collector (EGTC) with $\mathrm{CO}_{2}$ as refrigerant is simulated in the TRNSYS ${ }^{\circledR}$ simulation software. Time step selection is an influential parameter, and the month of June $(3,624-4,344 \mathrm{~h})$ was selected to observe system performance in Multan, Pakistan. This period has been chosen to be the peak of the summer season with maximum available solar insolation in hot areas in Pakistan. The system consists of three major loops: $\mathrm{A} \mathrm{CO}_{2}$ loop for harnessing solar thermal energy through EGTC, a hot water stream loop for operating absorption chiller and an auxiliary furnace is used for the time when enough solar energy is not available; the third one is building air loops. The TRNSYS simulation diagram of the system is shown in Figure 5.

The rated capacity of the absorption chiller is $27.78 \mathrm{~kW}$ with a coefficient of performance selected as 0.6 for a single-effect

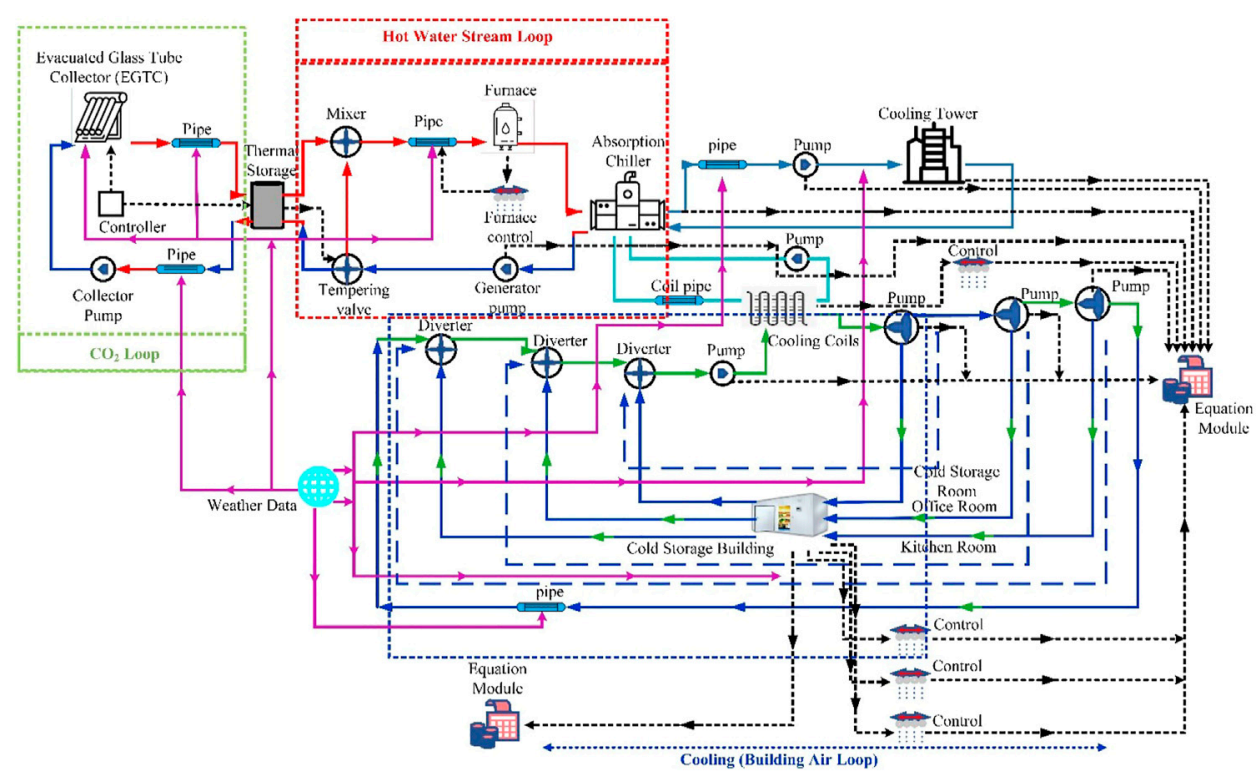

FIGURE 5 | Solar thermal air conditioning system using $\mathrm{CO}_{2}$ as a mediating fluid. 


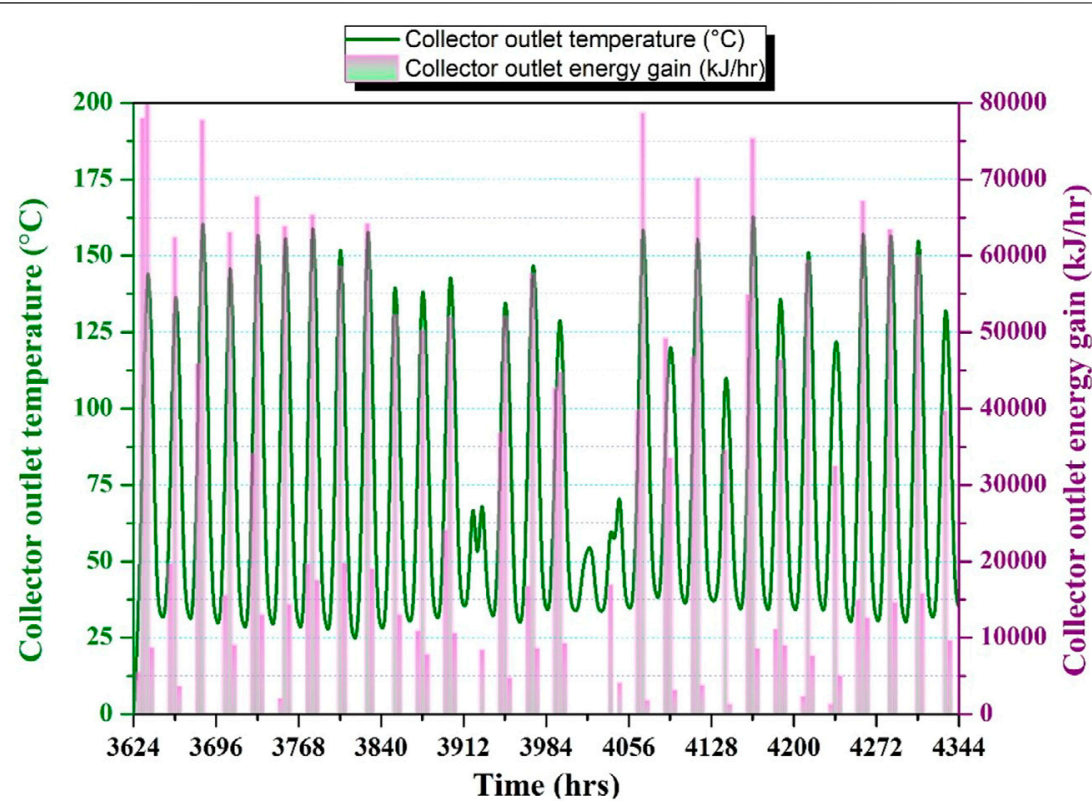

FIGURE 6 | Cooling outlet temperature and energy gain.

absorption chiller. A steam fired furnace is also used to provide enough input steam to the absorption chiller when solar isolation is not present. Solar energy is harnessed with EGTC using $\mathrm{CO}_{2}$ as a mediating fluid. The results are generated for the hot climate of Multan (Latitude $30.1575^{\circ}$ and Longitude $71.5249^{\circ}$ ), Pakistan. The temperature of $\mathrm{CO}_{2}$ leaving the EGTC and its useful energy gain is shown in Figure 6. Figure 7 presents the cooling coil outlet air temperature. It shows that cooling outlet temperature changes between -50 and $35^{\circ} \mathrm{C}$.

Figure 8 show the graph of the air temperature in different rooms of the cold storage buildings. The average obtained temperatures of the three rooms, cold storage room, office, and kitchen, were $18.43,26.25$, and $29.83^{\circ} \mathrm{C}$, respectively. The average ambient temperature and the EGTC output temperature

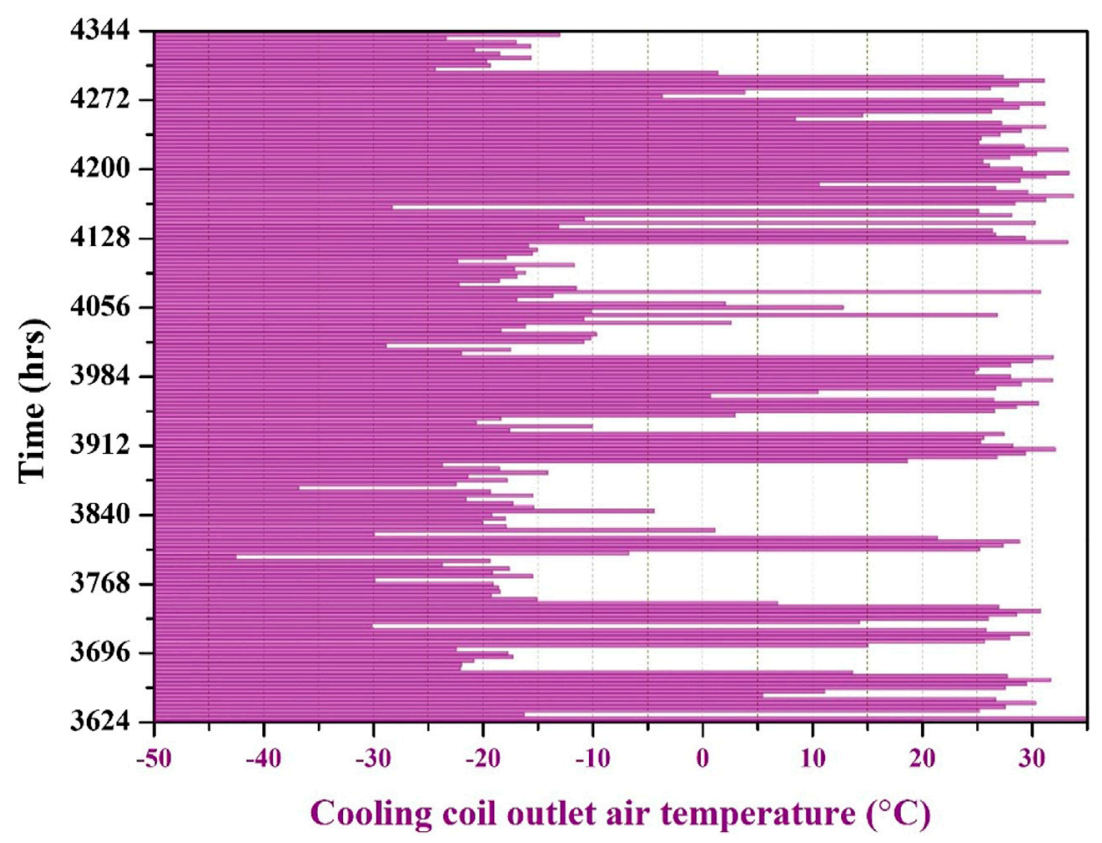

FIGURE 7 | Cooling coil outlet temperature $\left({ }^{\circ} \mathrm{C}\right)$. 


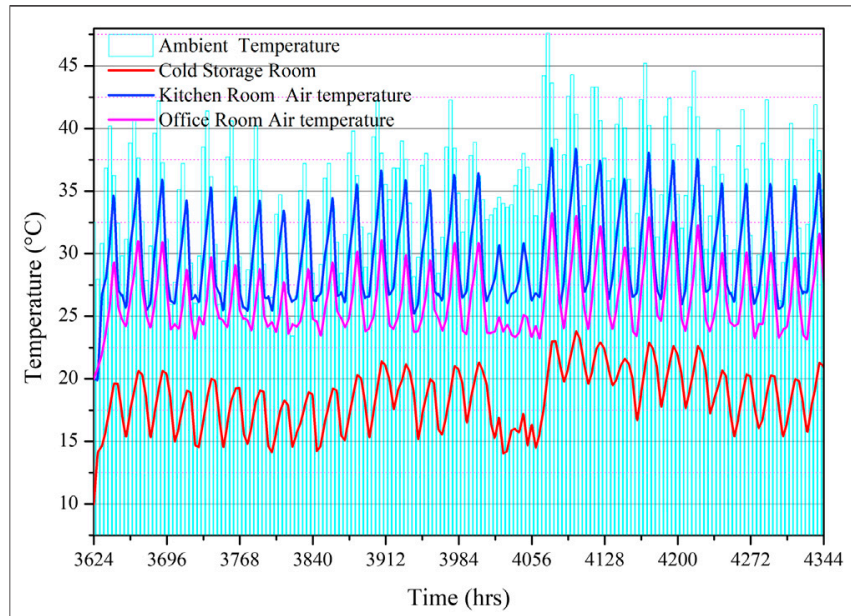

FIGURE 8 | Ambient air, cold storage, office and kitchen room temperature $\left({ }^{\circ} \mathrm{C}\right)$.

were 35.05 and $74.08{ }^{\circ} \mathrm{C}$ with an average EGTC outlet energy gain being $13,437.8 \mathrm{~kJ} / \mathrm{h}$ for the whole month. Figure 8 shows that the room temperature of the kitchen is slightly higher than those of the other rooms, as it is simulated for the kitchen room considering the heat from the burning stove.

\section{Business Model for Solar Thermal Cooling}

A business model defines as a design how a firm makes and conveys a value to its customers and a procedure to capture a share of that value. It is a coordinated set of components enveloping the flows of costs, revenues, and benefits (Teece, 2018). The business's success depends as much on a business model and execution which it does on the choice of technologies and the activity of tangible assets and resources. The business model gives a pathway by which technological advancement and expertise gained using tangible and intangible resources are transformed into a profitable output (Teece, 1986; 2006). The importance of learning a startup for a researcher or creator before entering the market is presented in Blank (2013). A much better know-how on a startup and a step-by-step guide for building a great company is provided by Steve Blank and Bob Dorf in Blank and Dorf (2012). The BMC used as a framework for analysis is adapted from Osterwalder and Pigneur (2010).

Leisen et al. (2019) have studied regulatory risk and flexibility of different sustainable business models in energy sectors. They have developed various BMCs for the marketing of electricity with renewables, virtual power plants, frequency regulation through large-scale batteries, energy performance monitoring, battery storage for PV self-consumption, and tenant PV electricity. They have adapted the BMC from Osterwalder and Pigneur (2010) and the risk matrix was also developed for each application. The interviews were conducted from experts to assess the risks regarding cost, revenue streams, customer segments and critical partners, channels and a significant focus of this study was only the German energy sector. They have suggested that markets in other countries have their own rules and regulations and structures like subsidy plan in Spain. Air conditioning and refrigeration demand highenergy consumption and the need to cover this energy consumption has become essential in the regions with hot weather conditions such as the Gulf, Africa, and the subcontinent. The application of RE for electricity generation, heating, and cooling has become more critical and is getting considerable attention of the researchers. The demand for energy for cooling and heating of fifty largest urban cities, focusing on the developing countries of the world, is discussed in Sivak (2009). The key outcomes of their research are: 38 out of 50 cities are from developing countries and most of them have warm to hot climates; all metropolitan areas in the top 30 except two are in developing countries that have more cooling demands than heating and the last outcome is that cooling demand is higher in 24 out of 38 metropolitan areas of developing countries. The Cooling Degree Days (CDD) for top 15 urban cities are illustrated in Figure 9. It is determined by subtracting $18^{\circ} \mathrm{C}$ from the average daily temperature (Sivak, 2009). The increase in income is the primary reason behind the substantial increase in energy demands in these cities. In cooling demand of top 30 metropolitan areas, the top one and six others are from India, six are from China, three are from Brazil, two are from Pakistan, and the United States. Bangladesh, Japan, Thailand, Philippines, Vietnam, Indonesia, Nigeria, Iraq, Congo DR, Egypt, and Iran have only one city in the top 30s. The metropolitan cooling demand of Mumbai alone is around $24 \%$ of the total United States. Most of these areas are from the subcontinent, China, Africa, and the Gulf.

The solar-based cooling system is introduced to encourage the use of green technology in the sustainability perspective. The key features of this product are universal availability of sunlight, a green refrigerant used, and little fuel cost. The expectation is that the solar-based air conditioning system can be made up at the lowest possible cost and at the bulk industrial level. Therefore, a business model for solar thermal cooling is developed and introduced in this article to give a proper knowledge design to the researchers in developing a business model design for the startup and commercialization of their project. Initially, the value proposition of the product is defined and customers are selected along with their needs in first canvas.

\section{Value Proposition Canvas}

The VPC gives insights into one's imagination about their customers' thinking and the thinking of a researcher who is in the making stage of his project (Osterwalder et al., 2014). The VPC focusing on the cold storages, supermarkets, and data centers is given in Figure 10. This canvas provides the set of the value proposition that this project can offer and what type of gain it produces for the customers and what major pains are going to be relieved. The right portion of the VPC is the customer segment in which the jobs of the core customers of the product are decided. It also includes: which key gains the customers want to get in their lives and what type of pains they are facing. After making the VPC, the ranking of the customer's jobs, pains, and gains is done. The top priority customer jobs are selected that one 


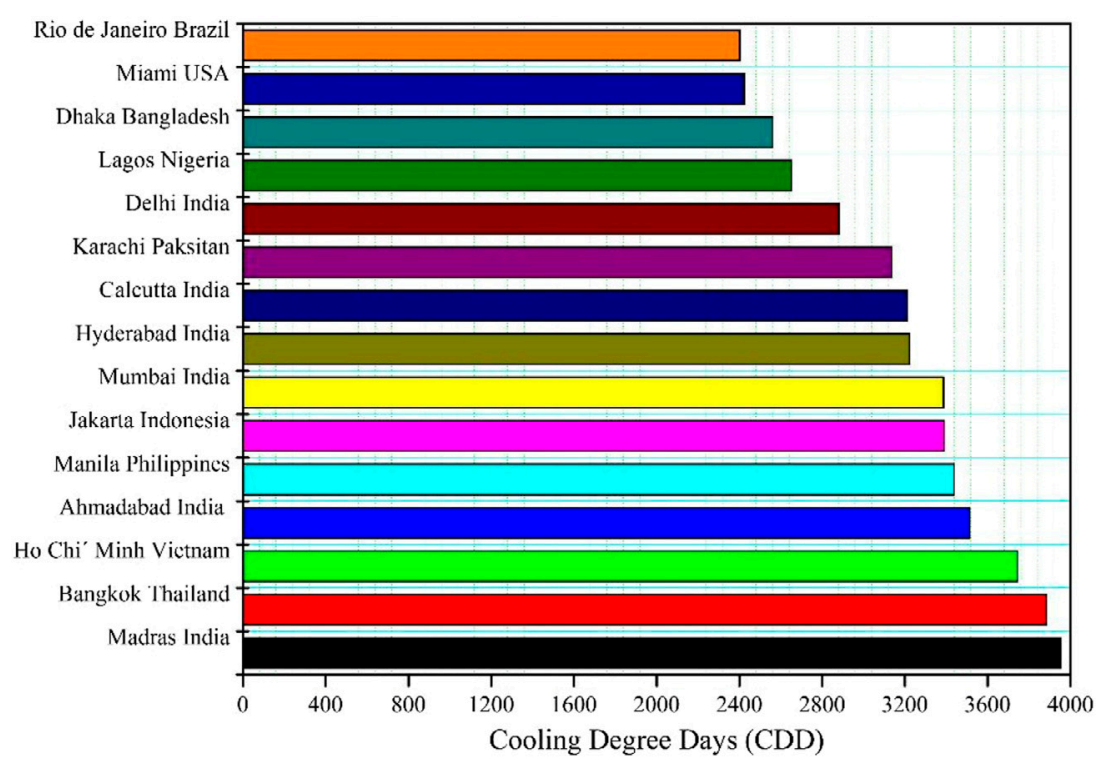

FIGURE 9 | Top 15 metropolitan areas with respect to Cooling Degree Days (CDD) Data Source: (Sivak, 2009).

wants to target first among all customer jobs. Similarly, the top priority pains and gains are chosen among all pains and benefits in their segments (Osterwalder et al., 2014). The VPC is made targeting cold storage, supermarket, and data center managers/ owners.

\section{Fit and Ranking Jobs, Pains, and Gains}

After making the VPC, the ranking of the customer's jobs, pains, and gains is done. The top priority customer jobs are selected that one wants to target first among all customer jobs. Similarly, the top priority pains and gains are chosen among all pains and benefits in their segments (Osterwalder et al., 2014). Then, the product market fit is checked by deciding that either the gains of the product are matching with the customer's gains, and similarly for pains. If the fit is very close between the value proposition and customer's needs, then the VPC is considered suitable for further business model design. If the value proposition of the product is not matching the customer's core gains and pains, then one should think about making a product that the customer wants rather than his own choice.

\section{Business Model Canvas}

The BMC consists of key partners, key activities, key resources, value proposition, customer relationships, channels, customer segments, cost structures, and revenue streams. The key partners that the project needs for its commercialization are air conditioning companies (Carrier, Daikin, LG, Samsung, Haier, Media, GREE, etc.),

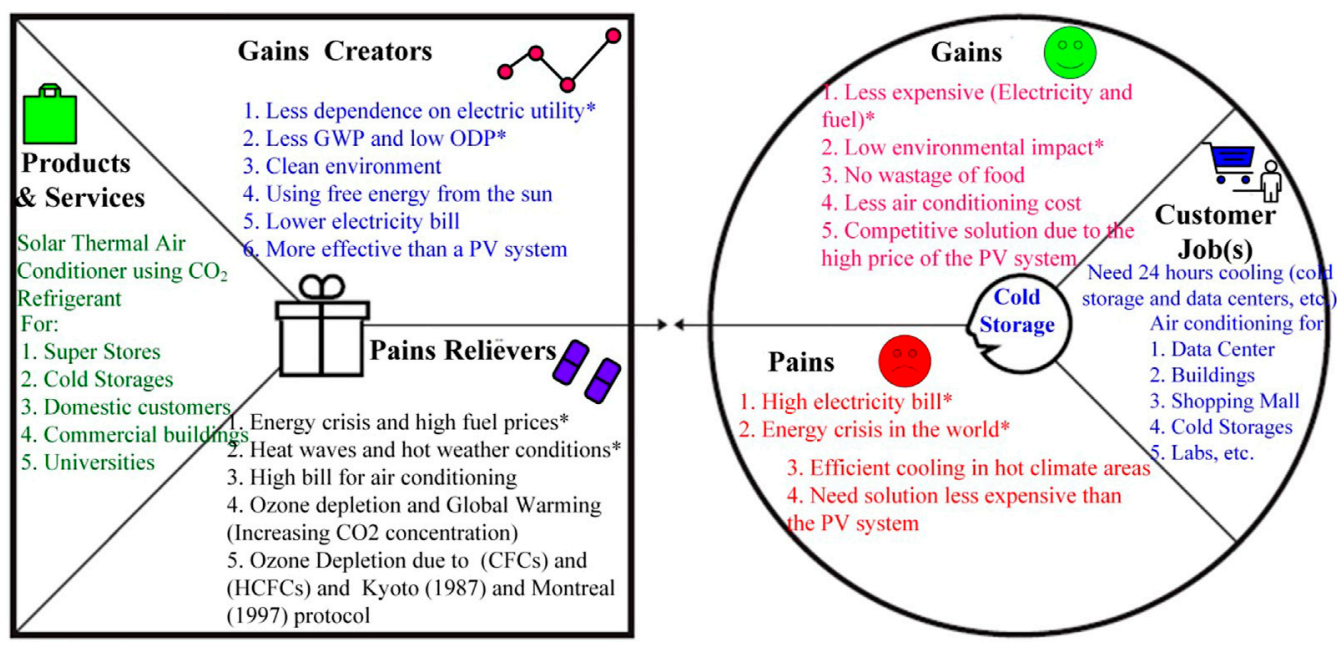

FIGURE 10 | The VPC for the solar thermal cooling adapted from (Osterwalder et al., 2014; Strategyzer A. G., 2018). 
consulting companies, cold storages, data centers, and research institutes under government organizations. The key activities such as research and development in laboratory, consultancy, and maintenance services will be required and accomplished using the essential resources that consist of trained technicians, physical space, necessary cooling, and solar thermal apparatus. The BMC, describing how we will achieve the scope of this project, is demonstrated in Figure 11. It shows the complete initial design of BMC to evaluate the initially supposed hypotheses. A good business model has a balance between the multiple requirements. It can be described entirely as feasibility (technical), desirability (customer), and viability (economics) of the product (Osterwalder and Pigneur, 2010).

\section{Desirability (Costumers)}

The desirability consists of value proposition, customer segment, customer relationship, and channels to provide the product to the customers. Together, they describe the desirability of the product to the customers. Initially, these customers are considered for this product; cold storages managers, Heating, Ventilation, and Air Conditioning (HVAC) engineers/managers of supermarkets, food stores, hotels, and commercial buildings. The solar thermal cooling application has a vast variety of consumers around the world as discussed earlier that most of them are in the subcontinent, Africa, Gulf, China, and United States (Sivak, 2009). It can be used for any place where cooling is required, such as homes, buildings of the school, colleges, and universities, etc. The principal customers who were considered in initial BMC design are given below:

- Small and large shopping malls

- Data centers

- Coupled with HVAC for large buildings (schools, colleges, hospitals, universities, etc.)

- Big vehicles such as trains and large buses

\section{Feasibility (Technical)}

The feasibility describes the physical, biological, contextual, and environmental requirements for innovation, what key activities are required to provide this product, and whom might we need as a partner. What key events are to perform every day to deliver the product value. Air conditioning companies, consulting companies, and cold storage manufacturing companies are considered to make the key partners for this product. The key resources needed to accomplish this product are trained technician, physical space, essential cooling equipment, solar thermal collectors, etc. The key activities to perform the research and provide the product to the customers are research and development in the laboratory, maintenance services, consultancies, and specific solution providing for the cooling requirement. These key activities, essential resources, and fundamental partners jointly give the technical feasibility of the product.

\section{Viability (Economics)}

The revenue and the cost structure model describe the viability of the product. The cost structure is the most important cost to make or to deliver the value proposition. The suggested prices are equipment costs, place rent, trained workers' salaries, marketing and advertising costs, patent, licensing, and shipment cost. The revenue will be collected by selling the assets such as a solar thermal air conditioner, retrofitting the existing systems, providing solutions, and consultancy services.

Three hypotheses were made initially and tested with the customers. After receiving the information from the customers, these hypotheses along with the BMC were updated accordingly. These hypotheses were used for creating significant questions to be asked to the desired customers.

\begin{tabular}{|c|c|c|c|c|c|}
\hline \multirow{2}{*}{$\begin{array}{l}\text { Key Partner } \\
\text { 1. Air conditioning } \\
\text { companies (Carrier, } \\
\text { Daikin, LG, } \\
\text { Samsung, Haier, } \\
\text { Media, and GREE, } \\
\text { etc.) } \\
\text { 2. Consulting } \\
\text { companies } \\
\text { 3. Cold storage } \\
\text { manufacturing } \\
\text { companies }\end{array}$} & \multicolumn{2}{|c|}{$\begin{array}{l}\text { Key } \\
\text { Activities } \\
\text { 1. Laboratory R\&D } \\
\text { 2. Consultancy } \\
\text { 3. Maintenance } \\
\text { 4. Solution } \\
\text { providers }\end{array}$} & \multirow{2}{*}{$\begin{array}{l}\text { Value } \\
\text { Propositions } \\
\text { 1. Low electricity } \\
\text { bill } \\
\text { 2. Lesser } \\
\text { dependence on } \\
\text { utility } \\
\text { 3. Low GWP } \\
\text { 4. Less food wastage } \\
\text { for cold storage } \\
\text { 5. Load shedding } \\
\text { solution } \\
\text { 6. Clean } \\
\text { environment }\end{array}$} & $\begin{array}{l}\text { Customer } \\
\text { Relationships } \\
\text { 1. Consultancy } \\
\text { 2. Solution } \\
\text { providers } \\
\text { 3. Trust } \\
\text { development }\end{array}$ & \multirow{2}{*}{$\begin{array}{l}\text { Customer } \\
\text { Segments } \\
\text { 1. Cold Storage } \\
\text { Managers } \\
\text { 2. Data Centers } \\
\text { Managers } \\
\text { 2. HVAC engineer/ } \\
\text { managers of super } \\
\text { markets and hotels } \\
\text { 3. HVAC manager } \\
\text { of commercial } \\
\text { buildings } \\
\text { 4. ICE factory } \\
\text { Managers }\end{array}$} \\
\hline & \multicolumn{2}{|c|}{$\begin{array}{l}\text { Key } \\
\text { Resources } \\
\text { 1. Trained } \\
\text { technicians } \\
\text { 2. Physical space } \\
\text { 3. Basic cooling } \\
\text { equipment }\end{array}$} & & $\begin{array}{l}\text { Channels } \\
\text { 1. Air conditioning } \\
\text { companies } \\
\text { 2. Consultancy } \\
\text { service } \\
\text { 3. Retailers }\end{array}$ & \\
\hline \multicolumn{2}{|c|}{$\begin{array}{l}\text { Cost Structure } \\
\text { 1. Equipment cost } \\
\text { 2. Trained workers salaries } \\
\text { 3. Consultancies }\end{array}$} & $\begin{array}{l}\text { 4. Place rent } \\
\text { 5. Marketing } \\
\text { 6. Shipment }\end{array}$ & \multicolumn{2}{|c|}{$\begin{array}{l}\quad \text { Revenue Streams } \\
\text { 1. Retrofit to existing systems } \\
\text { 2. Selling assets } \\
\text { 3. Providing consultancy } \\
\text { services }\end{array}$} & \\
\hline
\end{tabular}

FIGURE 11 | First BMC describing the feasibility, desirability, and viability of solar thermal cooling adapted from Osterwalder and Pigneur (2010), Van Der Pijl et al. (2016a), Strategyzer AG. (2018). 
Hypothesis-1: Current energy crisis and increasing fuel prices in the world.

Hypothesis-2: Efficient cooling using solar thermal air conditioning.

Hypothesis-3: Impact of air conditioning on climate.

\section{Customer Discovery Interviews}

Following an interpretive paradigm, researchers conducted an exploratory qualitative study. A convenient sampling strategy was employed. A sample of 10 respondents was selected from 150 companies based on cold storages, data centers, shopping malls in Pakistan, UAE, Saudi Arabia, Bangladesh, and Canada. Data were collected through semistructured interviews and a set of interview questions was guided by the advancement found in literature review and research objectives. Interviews were conducted face-to-face and on phone calls as per convenience of the respondents and the researchers. All interviews were audio-recorded and transcribed later. Data were analyzed following the approach of constant comparison analysis. Multiple readings of the data led to the process of coding through breaking up the text into codes which were reduced into manageable major themes. These customer's discovery interviews were conducted to validate the initial hypotheses and first business model. The primary consideration for conducting the interviews and getting more knowledge of a person is suggested in Constable (2012) and Constable et al. (2014). The key insights of some useful customer interviews (mostly in person) are presented in Table $\mathbf{1 .}$

\section{Who Are New Customers?}

Cold storage owners/managers, HVAC managers/engineers of chemical storages, biological clean rooms, ice production units, morgues/mortuary, testing labs, perishable goods, production/ processing units, and environmental control units are the new customers for this product.

\section{What Is This Product?}

The product will be a solar thermal air conditioning system using Natref $\left(\mathrm{CO}_{2}\right)$.

\section{Why Customer Would Buy This?}

- The cost of only cooling equipment of $75 \mathrm{~kW}$ capacity for cold storage is approximately 60 million PKR (price obtained from local suppliers).

- It is a green product having no environmental impact due to the use of Natref $\mathrm{CO}_{2}$.

- The cold storage also requires a back-up generator of almost 100,120 , or $240-275 \mathrm{kVA}$ (depending on their load) with the fuel supply. The estimated costs are around 2.0-3.0 million PKR and 4.0-5.0 million PKR for a 120 and $275 \mathrm{kVA}$ generator. The maintenance and running fuel costs are also present (Whatprice, 2020a; 2020b).

- The customers would want to buy this due to the features like free air conditioning from solar energy use, very low utility bills, and no constraints of Montreal and Kyoto Protocols due to the use of this product.

\section{Design Criteria Canvas}

The design criteria canvas helps in deciding the MVP. The MVP would be the product which has (must have) and (should have) qualities or only (must have) qualities of the product (Van Der Pijl et al., 2016b). After making the first MVP based on customer discovery interviews, the product can be upgraded by adding the (should have) or (could have) features in it. The design criteria canvas explains the qualities of MVP and its upgraded features for a project of solar thermal cooling using Natref $\mathrm{CO}_{2}$. Figure 12 shows the design criteria canvas by showing the features of MVP. Four "must haves," and non-negotiables features are selected: i) only air conditioning and comfort cooling for buildings, ii) solar thermal system using preferably a natural refrigerant $\left(\mathrm{CO}_{2}\right)$, iii) a minimum capacity, which can be connected with a thermal system for air conditioning, and iv) it must follow the recommendations of the Montreal and Kyoto protocol. "They should haves and important features" are: i) utilization of maximum free energy, ii) better than existing absorption units, iii) cooling, as well as heating, iv) after prototype, must have low cost, and v) easy installation. "They could have and optional features" are: i) retrofit existing cold storages and other units, ii) incorporating the existing HVAC units, iii) hybrid systems using PV panels (Almasri et al., 2021), and iv) smaller units. "They won't have" thing that is defiantly not included in the project are: i) use of harmful refrigerants, ii) total dependence on electrical utilities, iii) energy wasting, and iv) too costly.

\section{Updated Business Model Canvas}

The business model was updated after some customer discovery interviews. The major changes that occur in the business model were in the customer section. We have found some more customers, such as HVAC managers/engineers in chemical storages, biological clean rooms, morgues, testing labs, perishable goods, production processing units, and environmental control units. The updated BMC after customer discovery interviews is shown in Figure 13. In project key partners section, air conditioning companies (Carrier, LG, Haier, Daikin, Acson, Green Air, PEL, Dawlance, Samsung, GREE, MIA Group, etc.), Air conditioning Consulting companies (DWP Group, MEA Group, Jaffer Brothers, Izhar Group, Zahid Brothers, etc.), and some government-sponsored companies such as AEDB were added.

These three new hypotheses were made after customer discovery interviews.

Hypothesis-1: The people in the world want to get rid of load shedding and summer heat.

Hypothesis-2: Data center managers require economic precision cooling for their data center.

Hypothesis-3: The customer needs a cheap air conditioning system that has no environmental impact.

\section{Pivot}

In the future, when the product has to face some problems and hurdles then how this product can pivot from these marketing trends. If a product cannot pivot then it cannot survive the variations in the market. The most significant transformation or pivot in a team's way of thinking is a) high-cost concern, b) as 
TABLE 1 | Key insights of some customer discovery interviews.

Name-designation company
Engr. Akmal M K
Business Manager, Denmark
Engr. Haider Saqfi
Manager Ops Data Center, Interactive Group of
Companies, Islamabad, Pakistan
Engr. W Abass
Associate Manager, Data Centers-APC by
Schneider Division, DWP Group, KSA
Engr. Ishtiaq Husain
GM Mech, National Center for Physics, Islamabad,
Pakistan
Engr. Devdatt

Mechanical Engineer (HVAC), Grand Hayat Dubai, Dubai, UAE

Mr. Nouman Khan

Manager, City Super Market, Qatar

Engr. Mahboob Nasir, Director Technical, Izhar

Group

Cold store suppliers

Ahtsham Dost

General Manager, Humak industries, MIA Group of Companies, Gujarat, Pakistan

Mr. Ahmed Murtaza, Manager, Cheema Cold Storage, Wazirabad, Pakistan

\section{Type}

Face-to-face

On call

Face-to-face Data center cooling knowledge

Face-to-face R\&D of solar collectors

Face-to-face

Solar thermal system for heating at Grand Hayat, Dubai

Face-to-face Super store information

On call

Refrigeration and air conditioning information

Face-to-face

Refrigeration and air conditioning information

Face-to-face Cold storage information

Face-to-face Cold storage information

\section{Key insights}

The diesel is not a RE fuel polluting environment

They used large chillers for their data center at Copenhagen, Denmark

The diesel generators simply double the cos Cost of AC system is 470 USD per kW, hence the cost is almost 2 million (PKR) for a $35 \mathrm{~kW}$ air conditioning system They are using $\mathrm{R} 410$ and $\mathrm{R} 407$ synthetic refrigerants Their company is working APC by Schneider for supplying data center equipment

They are providing direct expansion cooling and precision cooling: Direct cooling to the heat dissipating equipment rather than to the whole room

The price of solar collector is high as compared to PV systems They are working on R\&D on solar thermal systems

They did not know about AC. Hence, he referred us to MIA group No energy crisis and load shedding situation in the UAE, but fuel prices are increasing

Therefore, they are harnessing solar energy through ETC for heating the water for their hotel-heating requirements

There are eight large chillers of 1,000 refrigeration ton each at Grand Hayat Dubai. A total of $28,000 \mathrm{~kW}$ capacity working on absorption system

They are using split units for their meat section

They have most of the items that do not require cooling

Obtained information about controlled atmosphere (CA) stores

Provide industrial refrigeration with the glycol ammonia system Regular high tech compressors operate with $\mathrm{NH}_{3}, \mathrm{R} 404, \mathrm{R} 507$ and $\mathrm{CO}_{2}$. Glycol and alcohol are used as intermediate fluids

Got more customer segment resulting from this interview, which was added to the new BMC

MIA group is working in refrigeration and air conditioning, and they have shown interest in partnering with this project

They are dealing mostly split units, and some absorption systems using $\mathrm{NH}_{3}$ and water as refrigerants. He has suggested some more potential customers for this product

They are mostly storing apple and bananas

The temperature for apple is set to $32-34^{\circ} \mathrm{F}$ and then maintained The storage temperature for banana is $60^{\circ} \mathrm{F}$. However, the storage of banana requires both heating and cooling during its storage time They have a dedicated 200 kVA transformer for their cold storage There are two $50 \mathrm{HP}$ compressor motors with a separate cooling water motor for the condenser. The cold storage is composed of one $15 \mathrm{HP}$ diffuser motors and three $7.5 \mathrm{HP}$ diffuser motors for all six rooms of different dimensions

There is no demand for vegetable storage in Wazirabad, as they are mostly consumed daily or wasted. This is due to the low sale price of these vegetables; farmers don't want to afford the extra storage price on them

This cold storage was only used to store the potatoes during its season from March to September

The storage temperature for potatoes is set to $32-34{ }^{\circ} \mathrm{F}$ and maintained

They have a dedicated $200 \mathrm{kVA}$ transformer for their cold storage. They also use a dedicated 250 kVA generator as a backup for cold storage solar thermal cooling is already available in the market so a product must have the ability to compete the competitors to survive, c) hybrid cooling costs less than the solar thermal air conditioning for a cold storage, and d) initially, MVP will be made and solar thermal cooling is more viable than making a huge system for air conditioning. 


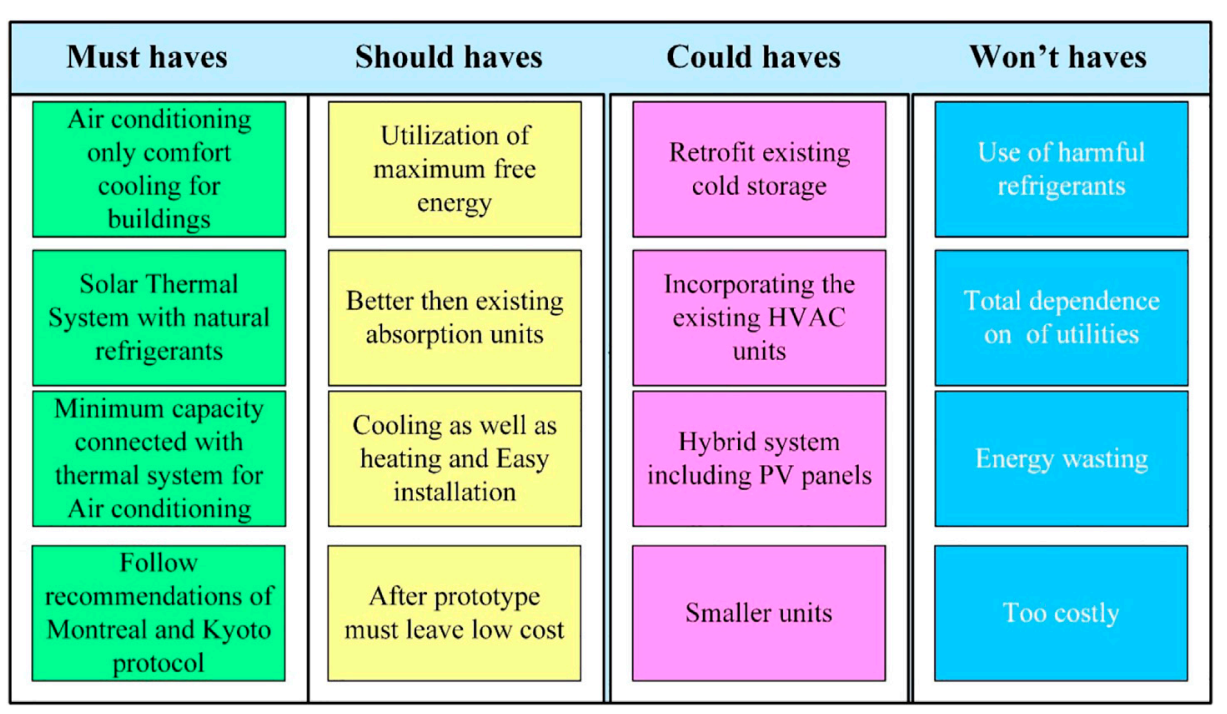

FIGURE 12 | Design criteria canvas, requirement of MVP adapted from Van Der Pijl et al. (2016b).

Considering the significant challenges for the future development of the technology and to bring it to market is the product cost and development of better refrigerants. Cost matters a lot for a customer to buy a product as most of the data center managers and suppliers told us that currently, they do not have enough resources to buy a large solar thermal air conditioner. The same was the case for cold storage owners. The trends and how to deal with these trends are presented in pivot canvas in Figure 14.

\section{Story-Telling Canvas}

To attain the attention of the customers toward this product of solar thermal air conditioning a Story Telling Canvas (STC) is made, the
STC is demonstrated in Figure 15. It includes the subject of the story, the goal of the story, and the audience of the story. The subject is the summer heat in hot climate areas and waste of fruits and vegetables due to the inadequate resources of cold storages and increasing fuels prices. The goal is to get rid of the energy crisis, better environment, reduction in food loss and hence boosting the economy of the country. The audience of the story is majorly the people living in the hot and humid climate regions of the world. About 38 metropolitan areas among the top 50 are in developing countries, and most of them are in warm and hot climates (Sivak, 2009). The top 10 urban areas with most cooling needs are Chennai India, Bangkok Thailand, Ho Chi Minh Vietnam, Ahmadabad India, Manila Philippines, Jakarta Indonesia, Mumbai

\begin{tabular}{|c|c|c|c|c|}
\hline \multirow{2}{*}{$\begin{array}{l}\text { Key Partner } \\
\text { 1. Air conditionıng } \\
\text { companies (Carrier, } \\
\text { LG, Haier, Daikin, } \\
\text { PEL, Dawlance, } \\
\text { Samsung, GREE, } \\
\text { and MIA Group, } \\
\text { etc.) } \\
\text { 2. Air conditioning } \\
\text { Consulting } \\
\text { companies (DWP } \\
\text { Group, Izhar Group, } \\
\text { Zahid Brothers, etc.) } \\
\text { 3. Cold storage } \\
\text { manufacturing } \\
\text { companies }\end{array}$} & $\begin{array}{l}\text { Key Activities } \\
\text { 1. Laboratory R\&D } \\
\text { 2. Consultancy } \\
\text { 3. Maintenance } \\
\text { solution providers }\end{array}$ & \multirow{2}{*}{\begin{tabular}{|l} 
Value \\
Propositions \\
1. Low electricity bill \\
2. Low dependence of \\
utility \\
3. Less food wastage \\
4. Load shedding solution \\
5. Clean environment \\
with low GWP \\
6. Precision cooling for \\
data centers \\
7. Hybrid cooling \\
8. Controlled Atmosphere \\
(CA) stores
\end{tabular}} & $\begin{array}{l}\text { 1. Consultancy } \\
\text { 2. Solution providers } \\
\text { 3. Trust development }\end{array}$ & \multirow{2}{*}{$\begin{array}{l}\text { Customer } \\
\text { Segments } \\
\text { 1. Cold Storages } \\
\text { Managers } \\
\text { 2. Data Center Managers } \\
\text { 3. HVAC Managers / } \\
\text { Engineers of } \\
\text { Chemical Storage, } \\
\text { Biological Clean Rooms } \\
\text { Ice Production } \\
\text { Morgues/Mortuary } \\
\text { Testing Labs } \\
\text { Perishable Goods, } \\
\text { Production Processing } \\
\text { Units } \\
\text { Environmental Control } \\
\text { Units }\end{array}$} \\
\hline & $\begin{array}{l}\text { Key } \\
\text { Resources } \\
\text { 1. Trained technicians } \\
\text { 2. Physical space } \\
\text { 3. Basic cooling } \\
\text { equipment } \\
\text { 4. Solar thermal } \\
\text { systems }\end{array}$ & & $\begin{array}{l}\text { Channels } \\
\text { 1. Air conditioning } \\
\text { companies } \\
\text { 2. Consultancy } \\
\text { service } \\
\text { 3. Retailers } \\
\text { 4. Online Marketing }\end{array}$ & \\
\hline \multicolumn{2}{|c|}{$\begin{array}{ll}\text { Cost Structure } & \\
\text { Equipment cost } & \text { 4. Place rent } \\
\text { Trained workers salaries } & \text { 5. Marketing cost } \\
\text { Consultancies } & \text { 6. Shipment cost }\end{array}$} & \multicolumn{2}{|c|}{\begin{tabular}{ll}
\multicolumn{1}{c}{ Revenue Streams } \\
1. Retrofit to existing systems & 4 \\
2. Selling assets & 5 \\
3. Providing consultancy services &
\end{tabular}} & e \\
\hline
\end{tabular}

FIGURE 13 | Updated BMC describing the feasibility, desirability, and viability of solar thermal cooling adapted from Osterwalder and Pigneur (2010), Van Der Pijl et al. (2016a). 


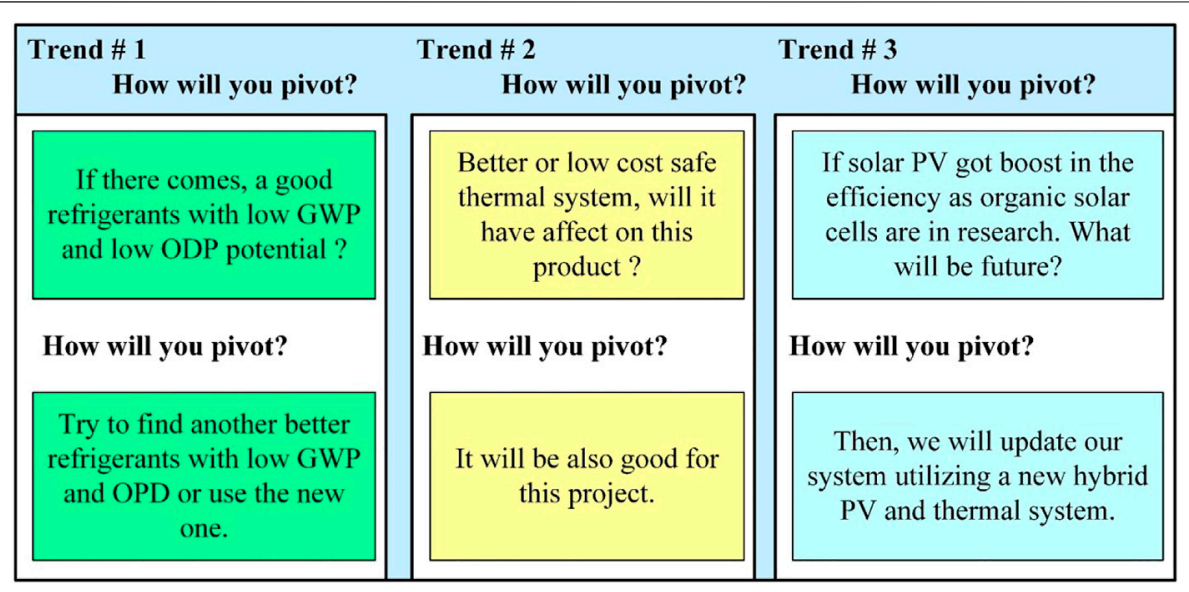

FIGURE 14 | Pivots and their solutions (Pivot Canvas).

India, Hyderabad India, Calcutta India, and Karachi Pakistan (Sivak, 2009). Roughly 1 Billion of the world population is living in these populated metropolitan areas (Elisha Sawe, 2019). The story is composed of five parts: i) before, ii) set the scene, iii) make the point, iv) conclusion, and v) after the story. The thinking of the audience in the world before they have experienced this story is: the audience wants to get rid of high fuel prices and energy crisis, they only know that air conditioning is only done using electricity and not from Sun energy directly, don't know about protocol and accords on refrigerants. The story will create a scene that they can get free cooling using Sun without using the harmful refrigerants, and onethird of the food is wasted due to inadequate air conditioning sources (Food and Agriculture Organization, 2019). The audience A-Ha moment is that they will get free cooling from the Sun. The story concludes that the Sun is there to give them cooling if utilized using thermal collectors and this cooling is free from harmful refrigerants. The people living in areas where electricity is not available would want to get this product. The story concludes that energy can be harnessed from the Sun and will be used to produce cooling and refrigeration. The cooling obtained from this product will not deplete the ozone layer, and customers will not be affected by the increasing fuel prices for their air conditioning-based load. After the story, the customers would like to buy the product depending on its price.

\section{Key Principles for Evaluation of Solar Thermal Cooling Design}

SHCS are the key solutions to match the rising demand for air conditioning. The sustainability and potential to reduce GWP are

\begin{tabular}{|c|c|c|c|c|c|}
\hline \multicolumn{2}{|l|}{ SUBJECT } & \multicolumn{2}{|l|}{ GOAL } & \multicolumn{2}{|c|}{ AUDIENCE } \\
\hline \multicolumn{2}{|c|}{$\begin{array}{l}\text { What is the story about? } \\
\text { 1. Air conditioning needs during the summer. } \\
\text { 2. Roughly one third of the food produced in the } \\
\text { world for human consumption every year - } \\
\text { around } 1.3 \text { billion tonnes - gets lost or wasted. } \\
\text { 3. Increasing fuel prices directly imposing high } \\
\text { electrical energy prices. }\end{array}$} & \multicolumn{2}{|c|}{$\begin{array}{l}\text { What do you want to achieve with } \\
\text { your story? } \\
\text { 1. To get rid of the energy of crisis } \\
\text { 2. Better environment } \\
\text { 3. Reduce food loss } \\
\text { 4. Increasing economy of the country }\end{array}$} & \multicolumn{2}{|c|}{$\begin{array}{l}\text { What is your story's audience? What } \\
\text { are their needs? } \\
\text { Cold storage, supermarkets, data } \\
\text { centers, and ice factory managers are } \\
\text { the primary audiences. } \\
\text { All people in the world who needs air } \\
\text { conditioning are our audience. }\end{array}$} \\
\hline BEFORE & 1. SET THE SCENE & 2. MAKE YOUR POINT & 3. CONCI & LUSION & AFTER \\
\hline $\begin{array}{l}\text { What does your audience } \\
\text { think, feel, know, want, } \\
\text { before they have } \\
\text { experienced your story? } \\
\text { 1. The audience in } \\
\text { world wants to get rid } \\
\text { of the energy crisis. } \\
\text { 2. Few of them know } \\
\text { Air-cod can only be } \\
\text { done using sunlight.. } \\
\text { 3. Don't know about } \\
\text { Kyoto and Montreal } \\
\text { protocols. }\end{array}$ & $\begin{array}{l}\text { What do you need to introduce. } \\
\text { What should be set up or } \\
\text { explained? } \\
\text { 1. Can get free cooling } \\
\text { using sun } \\
\text { 2. One-third of the food } \\
\text { is wasted due to } \\
\text { inadequate air } \\
\text { conditioning sources. } \\
\text { 3. World top companies } \\
\text { are using Green energy. } \\
\text { Like } \\
\text { Grand Hayat Hotel, } \\
\text { Dubai is getting using } \\
\text { hot water from solar } \\
\text { thermal energy. }\end{array}$ & $\begin{array}{l}\text { 1. You can get } \\
\text { cooling from the sun. } \\
\text { 2. Your electricity } \\
\text { bill will be less. } \\
\text { 3. Not to worry about } \\
\text { high fuel prices and } \\
\text { wastage of valuable } \\
\text { food } \\
\text { 4. Better climate with } \\
\text { low GWP and low } \\
\text { ODP refrigerants. }\end{array}$ & $\begin{array}{l}\text { The end of yo } \\
\text { What is the co } \\
\text { What is your } \\
\text { action? } \\
\text { 1. Energy c } \\
\text { harness frot } \\
\text { in the form } \\
\text { thermal ene } \\
\text { 2. Refrigera } \\
\text { not deplete } \\
\text { layer. } \\
\text { 3. Fuel pric } \\
\text { not affect a } \\
\text { conditionin }\end{array}$ & $\begin{array}{l}\text { story? } \\
\text { clusion? } \\
\text { ll of } \\
\text { be } \\
\text { the sun } \\
\text { y. } \\
\text { will } \\
\text { bills. }\end{array}$ & $\begin{array}{l}\text { What does your audience think, } \\
\text { feel, know, want, after they have } \\
\text { experienced your story? } \\
\text { 1. It is useful knowledge, } \\
\text { and we will buy it. } \\
\text { 2. The best solution for } \\
\text { fewer bills through green } \\
\text { energy. } \\
\text { 3. Best for regions where } \\
\text { no electricity is yet } \\
\text { available. } \\
\text { 4. We will contribute to the } \\
\text { betterment of the } \\
\text { atmosphere. }\end{array}$ \\
\hline
\end{tabular}

FIGURE 15 | Story telling Canvas (Van Der Pijl et al., 2016a; Design a Better Business, 2018). 
the significant reasons that SHCS are included in the IEA SHCS Strategic Plan (Murphy and Secretariat, 2011; Guthrie, 2014). Many SHCS tasks involving solar air conditioning have been completed, and some of them are in construction stages. Owing to the IEA cooperative international efforts, these projects have emerged from the R\&D to demonstration and now in the market. Ten vital qualitative principles for successful design and operation of SHCS are demonstrated in Neyer et al. (2018). After making the BMC, the key features of the proposed projects are also discussed with these ten key principles. These fundamental principles are beneficial in defining the MVP for this project. These ten key principles are summarized as follows:

0: Reduction in demand for energy before applying RE.

1: Select an application which can employ high annual solar energy.

2: Avoid employing fossil fuels for backup energy supply.

3: Design the project to meet the full heating/cooling demand.

4: Cooling should be wet (water-based cooling tower).

5: Design of ETC to work at an average solar radiation level.

6: Simple and compact flowsheet.

7: Thermal storage capability should match the requirement of heating and cooling.

8: It uses minimum power.

9: It should have minimum heat losses.

10: Use suitable resources for planning, monitoring, and executing the project.

These key features of these projects are also arranged under essential (Should or must haves features), Important features (Could haves features) and controversial (Won't haves features) are demonstrated in Figure 16.

\section{BUSINESS MODEL FOR SOLAR THERMAL COOLING IN PAKISTAN}

\section{Current Energy Scenario of Pakistan}

In the past two decades, Pakistan has faced a severe energy crisis in the form of electricity shortfall due to increased fuel prices, a reduction in hydropower capacity, and a growing population. Electric utilities are reaching their peak load in scorching summer, and are frequently encountered with brownout and load shedding situations. Hence, these are barely proficient in meeting their peak demand. The energy sector in Pakistan heavily depends on fossil fuel for its primary and secondary energy demand (Ghafoor and Rehman, 2016). The total primary supply during 2016-2017 was 80.9 Million tons of oil equivalent (Mtoe) with a growth rate of $6.5 \%$ per annum (BP, 2018). The energy mix of Pakistan in the years of 2016 and 2017 is majorly based on the oil, gas, and coal-based fuels with 87.53 and $88.12 \%$ share of use in the 2016 and 2017 of these fossil fuel resources (BP, 2018). The full energy mix for 2016 and 2017 is presented in Figure 17. It shows the percentage share of different energy resources used in Pakistan for its primary energy demand. The share of hydropower is increased between these 2 years, and however, all other sources got boast in their respective percentage. The indigenous fossil fuel resources are limited in Pakistan, and Pakistan imports the maximum fossil fuel for power generation which halts the economy of the country.

Total electricity production has risen from 118.5605 TWh to 123.9275 TWh from 2016 to 2017, respectively. In contrast, the hydroelectric generation has decreased from 34.27 TWh in 2016 to only 30.8195 TWh in 2017 (BP, 2018). In 2020, the share of hydroelectric generation was only $30.8 \mathrm{TWh}$, whereas total electricity generation was around 136.3 TWh. This depicts an alarming factor for the future of hydropower in Pakistan.

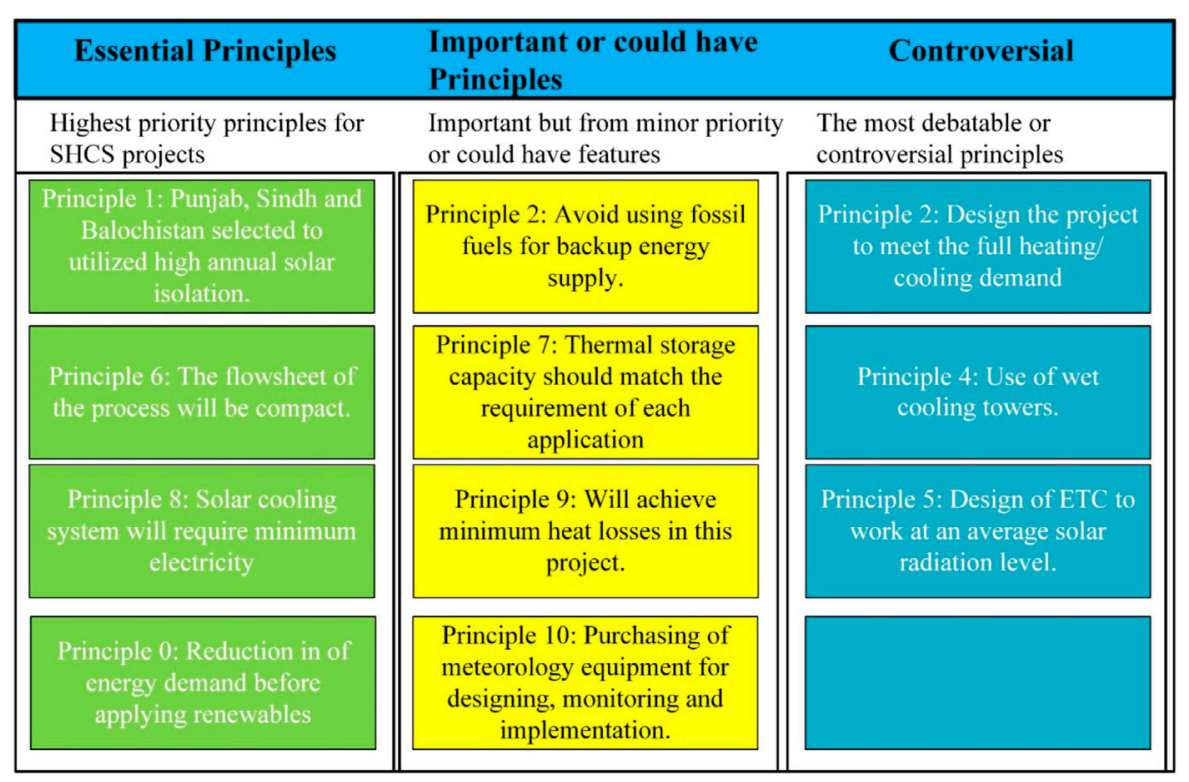

FIGURE 16 | Design criteria for MVP using three categories of 10 key principles. 


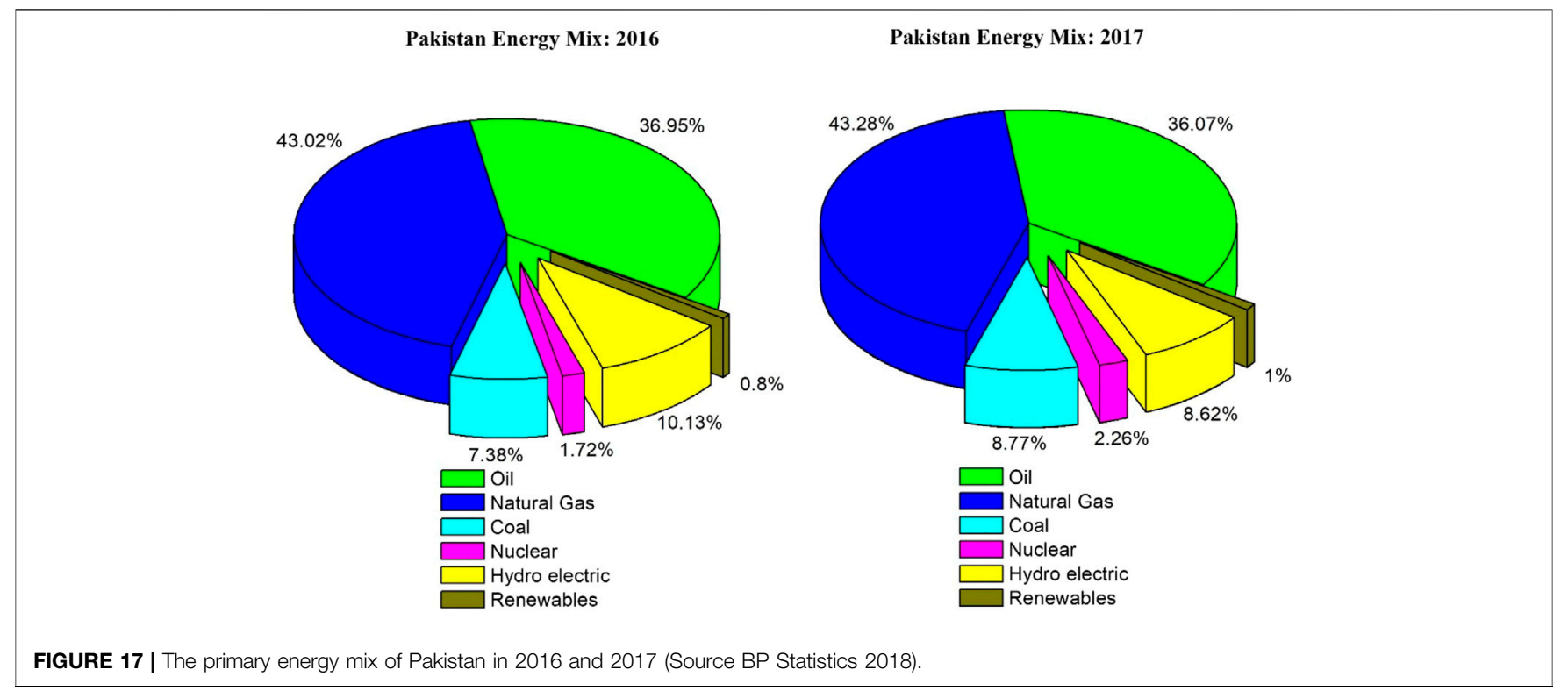

The difference between installed capacities and load demand in Pakistan was 2,645 and 6,151 MW in 2007 and 2011, respectively (Khalil and Zaidi, 2014). The shortfall was fluctuating between 4,000 and 7,000 MW during the past 5 years in the summer season. This gap is also present in the winter season due to the low level of water in dam reservoirs and shortage of natural gas due to increased domestic consumption. A shortfall of 4,786 MW was reported in 2017 (Dawn, 2017). Although the difference is reduced to $355 \mathrm{MW}$ in 2018, as reported on July 25,2018 the demand for electricity was $23,055 \mathrm{MW}$ and electricity generation was 22,700 MW (Pakistan Today, 2018). This is due to the reason that many oil and gas-powered plants were added to the national grid.

\section{Solar Energy Potential in Pakistan}

Pakistan has tremendous solar resources, suitable for both solar PV and solar thermal applications (Ahmed and Ulfat, 2004; Sheikh, 2010; Shaikh et al., 2013). Pakistan is blessed with $5.5 \mathrm{kWh} / \mathrm{m}^{2} /$ day average available solar insolation with an annual mean sunshine duration of $8-10 \mathrm{~h} /$ day throughout the country (Shamshad, 1998; Ulfat et al., 2012). According to research comprising the meteorological data of almost 30 years, Pakistan have the highest solar radiation intensity of $339.25 \mathrm{~W} / \mathrm{m}^{2}$ at Gilgit and lowest $76.49 \mathrm{~W} / \mathrm{m}^{2}$ at Cherat (Adnan et al., 2012). The average amount of solar radiation intensity (W/ $\mathrm{m}^{2}$ /day) in Pakistan is ranging from 1,500 to 2,750 (Adnan et al., 2012). The utilization of RE through solar and wind was scarce in

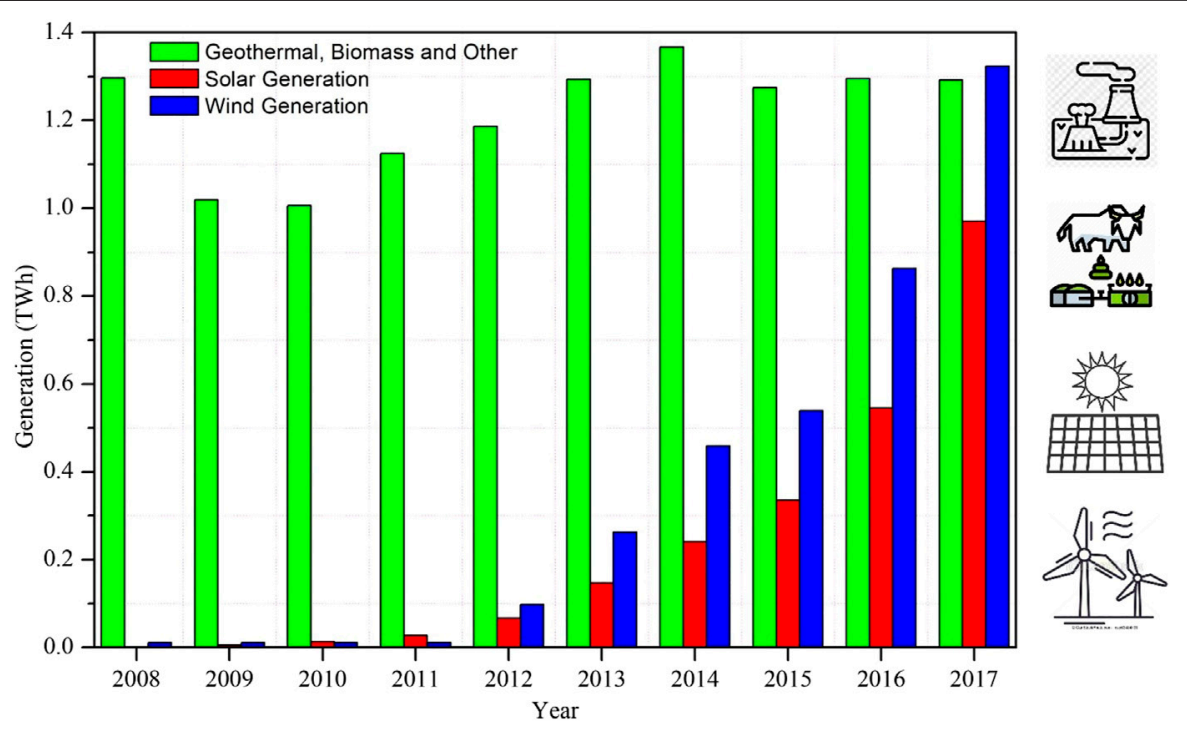

FIGURE 18 | RE generation in Pakistan in the past decade [Source Data: BP Statistics 2018 (BP, 2018)]. 


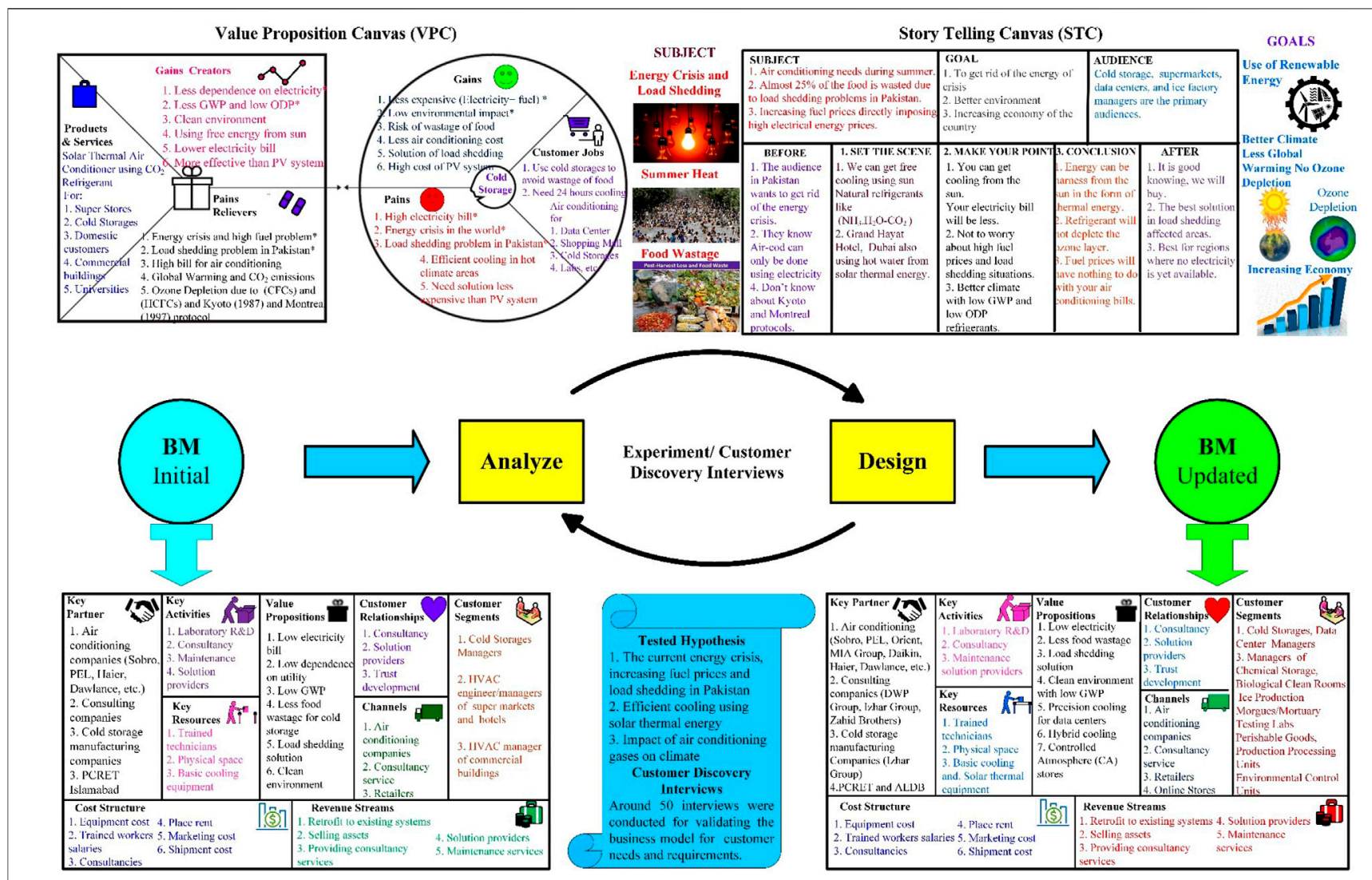

FIGURE 19 | Business model for solar thermal air conditioning in Pakistan.

Pakistan before 2012. In 2012, the electricity generation by solar and wind power was around only $0.1651 \mathrm{TWh}$. However, after 2012 it has got boast and now reached to 2.293 TWh (BP, 2018).

The progress in RE use is still at a languid pace. However, the Pakistan government has proposed to eliminate taxes on solar and wind energy equipment in the country, and there is considerable increase being seen in the use of RE in domestic and commercial applications (Mukhtar, 2019). The Alternative Energy Development Board (AEDB), working under the Ministry of Energy and Power Development of Federal Government, is working on the development of RE in Pakistan. Almost 28 projects are under development with Letter Of Intent issued from AEDB. There are 28 projects of solar PV with 956.8 MW under construction. Similarly, five wind and 28 Biomass projects with 215 and 965.2 MW capacities, respectively, are under development. They have identified almost 815 sites for micro-hydel projects with a total potential of $3,100 \mathrm{MW}$ of power, the only KPK government had taken the initiative of making nearly 350 micro-hydel projects, but only 232 micro hydel projects were completed during 2013-2018, according to their claims. Eight large projects with $271.2 \mathrm{MW}$ capacity are under construction by the KPK government (AEDB, 2018). Pakistan Council of Renewable Energy Technologies (PCRET) has been working in RE since 2001 (PCRET, 2006). The installed RE projects by the PCRET in Pakistan are summarized in Supplementary Table 3. AEDB and PCRET mostly do the significant R\&D on RE. Both of these government departments are serving for the development of RE applications in Pakistan. Apart from this, many institutes such as NUST, COMSATS, and UET are also working on RE technologies. The utilization of RE through solar and wind was scarce in Pakistan before 2012. In 2012, the electricity generation by solar and wind power was around only 0.1651 TWh. However, after 2012 it has got boost and now reached to 2.293 TWh (BP, 2018). The status of renewables in Pakistan in past few decades is presented in Figure 18.

\section{Business Model for Solar Thermal Cooling in Pakistan}

People in Pakistan are suffering an unconventional energy crisis in the form of load shedding and sudden fuel shortage in their daily life. This severe energy crisis in Pakistan has changed people's minds to use electrical generators in the absence of electricity. Consequently, this is imposing a harmful impact on the climate of Pakistan due to the excessive use of oil in long load shedding hours in Pakistan. In the past decade, the emergence of RE technologies has got vital growth in Pakistan. But there is still a need for a compact design solution to get rid of the load shading condition in hot summer days. Hence, solar-based cooling systems are the best choice to comfort their warm days and to reduce their energy crisis. 
In Pakistan, there does not exist any indigenously developed solar thermal air conditioning system (even for demonstration purposes). Moreover, no known attempts have been made to evaluate the performance of a solar thermal system for the cooling application. Similarly, innovative studies for developing a business model also lack in the country.

The following three hypotheses were made before the customer interviews in Pakistani Market.

Hypothesis-1. The current energy crisis, increasing fuel prices and load shedding in Pakistan.

Hypothesis-2. Efficient cooling using solar thermal energy.

Hypothesis-3. Impact of air conditioning gases on climate.

Around 50 interviews were conducted for validating the business model for customer needs and requirements. It was found that the $\mathrm{R} \& \mathrm{D}$ for solar cooling is not yet started due to the limited resources, lack of training in SHCS, and less interest of researchers due to limited funding. Even though Pakistan has great potential for solar energy as discussed earlier. A complete business model is presented in Figure 19. It includes the initial business model and analyzing this business model through customer discovery interviews and then designing the updated business model for Pakistan. It also includes VPC and STC focusing on the energy scenario and load shedding situation in Pakistan.

\section{Reducing Global Warming and Climate Change}

Being full signatory of Paris Agreement (2016) (United Nations), Montreal Protocol (1992) (United Nations, 2019), and Kyoto Protocol (2005) (United Nations, 2005), it is an international obligation that Pakistan should use environmentally benign refrigerants in the HVAC products used in Pakistan. Pakistan has successfully phased out the first generation of ozonedepleting substances (ODSs) such as CFCs, Halons, carbon tetrachloride (CTC), and methyl bromide. It is now working on the phase-out of the second generation of ODSs (United Nations, 2019). According to the Paris agreement (2016), it was mutual consent of all signatories that country shall make use of RE systems and reduce the carbon emission from fossil fuel burning so that accumulated efforts may be made to sustain the planet earth's crest temperature below $1.5^{\circ} \mathrm{C}$ by 2030 . This situation has given a way to the naturally occurring refrigerants to replace the CFCs and HCFCs.

Pakistan is also suffering from the drastic effects of environmental changes, the winter smog condition in Lahore and other Punjab is no doubt due to these changes, which are mostly referred to the cutting of trees, burning the remaining of the wheat crop in Indian Punjab (Abas et al., 2019c), increased fuel consumption, and waste gases from industries (Niaz and Zhou, 2014; Riaz and Hamid, 2018). This has increased the amount of $\mathrm{CO}_{2}$ and GHG emissions in the air and caused long summer days and smog conditions due to increasing GWP in Pakistan. Coal-fired power plants of the neighboring countries are considered the cause of this smog coming through the regional wind drives. Similarly, many heat waves in Karachi are also occurring more frequently than in the past. In 2015, a severe heatwave with the highest temperature of $49^{\circ} \mathrm{C}$ was observed in Baluchistan and Sindh, which has resulted in the death losses of around 2,000 persons due to dehydration and heat stroke (Haider and Anis, 2015; Mansoor, 2015).
In April 2017, another heat wave affected Punjab and southern Pakistan with maximum temperature touching $51^{\circ} \mathrm{C}$ in Larkana, Sindh (Nation, 2017; Pakistan Today, 2017). Currently, Karachi is also facing a heat wave at the start of May 2019. Authorities and hospitals are on high alert to meet this emergency in southern Pakistan during the heat wave (Pakistan Today, 2019).

\section{Impact of Commercialization of Technology}

This research will have a promising impact on the development of Pakistan. First, it will show a way to the researchers and students to work on the solar thermal applications. Second, it will be precious for the ordinary people of Pakistan in hot weather areas such as in Sindh, Baluchistan, Punjab, for providing a decent atmosphere to the people of Pakistan. The installation of solar thermal cooling using absorption cycle for industrial applications is demonstrated in Akhtar et al. (2015). Their results depict 69\% solar factor and around 4 years of payback period which shows the significant potential of solar thermal cooling in Pakistan. The calculations for the solar factor are presented in Akhtar et al. (2015). The increasing electricity prices and reduction in solar collector prices can reduce the payback period even more. Some other benefits of solar thermal cooling development and scope are summarized in the following subsections.

The local manufacturing of this project will create employment and will reduce poverty and hunger in Pakistan. The commercialization of this technology in the form of solar air conditioning for domestic, commercial applications, and cold storages will increase the economy of the country.

The significant impact of commercialization of this project is mentioned in the following points.

- Development in the field of solar thermal technologies by utilizing local raw material.

- Provide job opportunities.

- Help in solving the energy crisis in Pakistan.

Reduce wastage of fruits and vegetables by solar-based cold storages

- Local manufacturing will increase the economy of Pakistan.

- Impact on domestic production and industrial opportunities.

\section{Implementation of the Project}

The novel features of the proposed solar thermal air conditioning system are: The system is efficient and flexible to work in the hot and humid region all over the world, the available sunshine is enough to produce much heat that will be incorporated in cooling systems. The system serves a dual purpose and has a wide range of applications. The system can be used for domestic heating in the winter season and air conditioning in the summer season. In summer, the system's heat pump can be used as an air conditioner. The high efficiency of the system will make it an ideal and practical choice for many domestic applications. The system is cheap and efficient. The system can easily be retrofitted/ integrated into any building. Although electric air conditioners are suitable, yet the overall efficiency of first transforming fossil fuel energy in electricity and then converting it for heating and cooling is quite low. Moreover, such a process is not environmentally benign due to the leaking of synthetic refrigerants. 


\section{CONCLUSION AND FUTURE PROSPECTS}

Solar thermal cooling technology is getting considerable attention due to high air conditioning demand in hot and humid climate and energy crisis. The problem caused by synthetic refrigerants (CFCs and $\mathrm{HCFCs}$ ) and $\mathrm{CO}_{2}$ emissions by fuels has influenced to force the world accords and protocols for the protection of the ozone layer and to reduce global warming. Therefore, first capturing the $\mathrm{CO}_{2}$ and employing it for a meaningful purpose of solar-assisted air conditioning can serve the environment. Currently, $\mathrm{CO}_{2}$ has been widely used in the world's largest markets such as Europe, Japan, China, North America, and Austria. However, a business model for the application of $\mathrm{CO}_{2}$ in solar-based refrigeration and air conditioning has not been developed yet. It also hinders its accelerated growth in the most populated hot climate areas such as South Asia, Middle East, and Africa. A solar thermal air conditioning system is developed and simulated in TRNSYS. The system captures solar energy through EGTC with refrigerant $\mathrm{CO}_{2}$ flowing through it. The heat is transferred to the storage heat exchanger-based storage tank. An absorption cooling chiller is applied to cool the cold storage room building. The building consists of three rooms: a cold storage room, an office room, and one adjacent kitchen. The collector outlet temperature, ambient temperature, cold storage room, office room, and kitchen room temperature were recorded throughout the whole month of June, and their average values are $74.08,35.05,18.43$, 26.25 , and $29.83^{\circ} \mathrm{C}$. Collector provides useful energy gain at an average rate of $13,437.8 \mathrm{~kJ} / \mathrm{h}$. Thus the results obtained through simulations are promising and this method can be adapted for cold storages in Pakistan.

However, developing a business model for a startup is necessary for the successful commercialization of the product. But unfortunately, due to the lack of experience of technical researchers about startups and commercialization, many products have not come into the market after their initial development. Hence, the successful startup, commercialization, and marketing of the product are necessary for the indefatigable efforts of the researchers. Initially, a researcher cannot hire a marketing team for his or her project. Even a market team cannot help him alone in developing the project. Sometimes joining a company and marketing and manufacturing the product with their investment is also a feasible option. However, a creator must go out there and meet the customers personally because only he is working on the research and development of the project and no other person can understand his product more than him. Customer discovery interviews are the key finding of this business model. It is necessary to update the initial BMC whenever we got any new insight about the product. The first launch of the product should be MVP because the owner cannot

\section{REFERENCES}

Abas, N., Kalair, A., and Khan, N. (2015). Review of Fossil Fuels and Future Energy Technologies. Futures. 69, 31-49. doi:10.1016/ j.futures.2015.03.003 give his all critical efforts in the first product. The customers would offer suggestions about their requirements and necessities to update the product. Hence, the MVP will be upgraded accordingly. Moreover, the solar thermal cooling projected is also tested on the same fundamental principle that is used by researchers to assess the IEA SHCS projects. The project key parameters and findings will be tested and demonstrated in the future. By adopting these simple methods, any innovative researcher can make his or her own business model for the successful commercialization of innovative products in the market.

\section{DATA AVAILABILITY STATEMENT}

The original contributions presented in the study are included in the article/Supplementary Material; further inquiries can be directed to the corresponding author.

\section{AUTHOR CONTRIBUTIONS}

ARK and SD conceived the idea and performed literature review and developed business model and wrote the manuscript. MS and AS helped in data curation and supervised the business model. NA performed data analysis, conducted interviews and helped in writing original manuscript. KK, SD and ARK performed customer discovery interviews to develop canvass.

\section{FUNDING}

This research work was in part supported by HEC TDF02-086.

\section{ACKNOWLEDGMENTS}

The authors sincerely thank Adam Klich, Technical Project Manager, and other RTI innovation advisors for their discussions and insightful advice for commercialization of new products under the PakistanUnited States Science and Technology Startup and Ideation Training Program. The authors also thank all the interviewees for their key insights and thoughts for developing the business model.

\section{SUPPLEMENTARY MATERIAL}

The Supplementary Material for this article can be found online at: https://www.frontiersin.org/articles/10.3389/fenrg.2021.671973/ full\#supplementary-material

Abas, N., Khan, N., Haider, A., and Saleem, M. S. (2017). A Thermosyphon Solar Water Heating System for Sub Zero Temperature Areas. Cold Regions Sci. Technology 143, 81-92. doi:10.1016/j.coldregions.2017.08.012

Abas, N., Khan, N., and Hussain, I. (2014). "A Solar Water Heater for Subzero Temperature Areas,". Progress In Sustainable Energy Technologies: Generating Renewable Energy 8, 369-377. doi:10.1007/978-3-319-07896-0_20 
Abas, N., Kalair, A. R., Khan, N., Haider, A., Saleem, Z., and Saleem, M. S. (2018). Natural and Synthetic Refrigerants, Global Warming: A Review. Renew. Sustainable Energ. Rev. 90, 557-569. doi:10.1016/j.rser.2018.03.099

Abas, N., Kalair, A. R., Seyedmahmoudian, M., Naqvi, M., Campana, P. E., and Khan, N. (2019a). Dynamic Simulation of Solar Water Heating System Using Supercritical CO2 as Mediating Fluid under Sub-zero Temperature Conditions. Appl. Therm. Eng. 161, 114152. doi:10.1016/j.applthermaleng.2019.114152

Abas, N., Khan, N., and Haider, A. (2019b). Thermosiphon Solar Water Heater Using CO2 as Working Fluid. United States Patent US 10281174.

Abas, N., Saleem, M. S., Kalair, E., and Khan, N. (2019c). Cooperative Control of Regional Transboundary Air Pollutants. Environ. Syst. Res. 8, 10. doi:10.1186/ s40068-019-0138-0

Abas, N., and Khan, N. (2014). Carbon Conundrum, Climate Change, CO2 Capture and Consumptions. J. CO2 Utilization. 8, 39-48. doi:10.1016/j.jcou.2014.06.005

Adnan, S., Hayat Khan, A., Haider, S., and Mahmood, R. (2012). Solar Energy Potential in Pakistan. J. Renew. Sustainable Energ. 4, 032701. doi:10.1063/ 1.4712051

AEDB (2018). Alternative Energy Development Board (AEDB), Ministry of Water and Power, Government of Pakistan. 2018. Available at: http://www.aedb.org (Accessed November 7, 2018)

Agyenim, F., Knight, I., and Rhodes, M. (2010). Design and Experimental Testing of the Performance of an Outdoor $\mathrm{LiBr} / \mathrm{H} 2 \mathrm{O}$ Solar thermal Absorption Cooling System with a Cold Store. Solar Energy. 84, 735-744. doi:10.1016/ j.solener.2010.01.013

Ahmed, F., and Ulfat, I. (2004). Empirical Models for the Correlation of Monthly Average Daily Global Solar Radiation with Hours of sunshine on a Horizontal Surface at Karachi, Pakistan. Turkish J. Phys. 28, 301-307.

Akhtar, S., Khan, T. S., Ilyas, S., and Alshehhi, M. S. (2015). Feasibility and Basic Design of Solar Integrated Absorption Refrigeration for an Industry. Energ. Proced. 75, 508-513. doi:10.1016/j.egypro.2015.07.441

Almasri, R., Alardhi, A., and Dilshad, S. (2021). Investigating the Impact of Integration the Saudi Code of Energy Conservation with the Solar PV Systems in Residential Buildings. Sustainability. 13, 3384. doi:10.3390/su13063384

Arora, R. C. (2012). Refrigeration and Air Conditioning. PHI Learning Pvt. Ltd. doi:10.4271/2012-28-0026

Balaras, C. A., Hans-Martin, H., Wiemken, E., and Grossman, G. (2006). Solar Cooling: an Overview of European Applications \& Design Guidelines. ASHRAE J. $48,14$.

Baniyounes, A. M., Ghadi, Y. Y., Rasul, M. G., and Khan, M. M. K. (2013). An Overview of Solar Assisted Air Conditioning in Queensland's Subtropical Regions, Australia. Renew. Sustainable Energ. Rev. 26, 781-804. doi:10.1016/j.rser.2013.05.053

Basit, M. A., Dilshad, S., Badar, R., and Sami ur Rehman, S. M. (2020). Limitations, Challenges, and Solution Approaches in Grid-connected Renewable Energy systemsLimitations, Challenges, and Solution Approaches in Grid-Connected Renewable Energy Systems. Int. J. Energ. Res 44, 4132-4162. 5033. doi:10.1002/er.5033

Benhadid-Dib, S., and Benzaoui, A. (2012). Refrigerants and Their Environmental Impact Substitution of Hydro Chlorofluorocarbon HCFC and HFC Hydro Fluorocarbon. Search for an Adequate Refrigerant. Energ. Proced. 18, 807-816. doi:10.1016/j.egypro.2012.05.096

Blank, S. (2013). Why the Lean Start-Up Changes Everything. Harv. Bus. Rev. 91, 63-72.

Blank, S., and Dorf, B. (2012). The Startup Owner's Manual: The Step-by-step Guide for Building a Great Company. BookBaby. Hoboken, NJ, United States: John Wiley \& Sons.

Bocken, N., Boons, F., and Baldassarre, B. (2019). Sustainable Business Model Experimentation by Understanding Ecologies of Business Models. J. Clean. Prod. 208, 1498-1512. doi:10.1016/j.jclepro.2018.10.159

Boudéhenn, F., Demasles, H., Wyttenbach, J., Jobard, X., Chèze, D., and Papillon, P. (2012). Development of a $5 \mathrm{~kW}$ Cooling Capacity Ammonia-Water Absorption Chiller for Solar Cooling Applications. Energ. Proced. 30, 35-43. doi:10.1016/j.egypro.2012.11.006

BP (2018). BP Statistical Review of World Energy, 1-56. Available at https://www. bp.com/en/global/corporate/energy-economics/statistical-review-of-worldenergy.html.

Calm, J. M. (2008). The Next Generation of Refrigerants - Historical Review, Considerations, and Outlook. Int. J. Refrigeration 31, 1123-1133. doi:10.1016/ j.ijrefrig.2008.01.013
Constable, G. (2012). 12 Tips for Early Customer Development Interviews (Revision 3). 2019. Available at: http://giffconstable.com/2012/12/12-tips-forearly-customer-development-interviews-revision-3/

Constable, G., Fishburne, T., and Rimalovski, F. (2014). Talking to Humans: Success Starts with Understanding Your Customers. New York, United States: Giff Constable.

Darkwa, J., Fraser, S., and Chow, D. H. C. (2012). Theoretical and Practical Analysis of an Integrated Solar Hot Water-Powered Absorption Cooling System. Energy. 39, 395-402. doi:10.1016/j.energy.2011.12.045

Dawn (2017). Power Cuts Return as Shortfall Touches 7,000 MW. 2018. Available at: https://www.dawn.com/news/1331738 (Accessed November 6, 2018).

Design a Better Business (2018). Storytelling Canvas. 2018. Available at: https:// designabetterbusiness.tools/dbb-tools/tools/storytelling-canvas/ (Accessed November 1, 2018).

Dilshad, S., Kalair, A. R., and Khan, N. (2020). Review of Carbon Dioxide (CO 2 ) Based Heating and Cooling Technologies: Past, Present, and Future Outlook. Int. J. Energ. Res 44, 1408-1463. doi:10.1002/er.5024

E891-87, A (1992). Tables for Terrestrial Direct Normal Solar Spectral Irradiance Tables for Air Mass 1.5 (Withdrawn 1999). West Conshohocken, PA. Available at: http://www.astm.org.

Edenhofer, O., Pichs-Madruga, R., Sokona, Y., Kadner, S., Minx, J. C., Brunner, S., et al. (2014). Technical Summary.

Elisha Sawe, B. (2019). World Atlas. The 10 Largest Cities in the World. Available at: https://www.worldatlas.com/articles/the-10-largest-cities-in-the-world. html. doi:10.1525/9780520950542

Food and Agriculture Organization (2019). Food and Agriculture Organization of United Nations. Key Facts on Food Loss and Waste You Should Know! Available at: http://www.fao.org/save-food/resources/keyfindings/en/ (Accessed May 5, 2019).

Gao, Y., Gao, X., and Zhang, X. (2017). The $2{ }^{\circ} \mathrm{C}$ Global Temperature Target and the Evolution of the Long-Term Goal of Addressing Climate Change-From the United Nations Framework Convention on Climate Change to the Paris Agreement. Engineering. 3, 272-278. doi:10.1016/j.eng.2017.01.022

Ghafoor, A., Rehman, T. u., Munir, A., Ahmad, M., and Iqbal, M. (2016). Ur, Munir, A., Ahmad, M., and Iqbal, MCurrent Status and Overview of Renewable Energy Potential in Pakistan for Continuous Energy Sustainability. Renew. Sustainable Energ. Rev. 60, 1332-1342. doi:10.1016/j.rser.2016.03.020

Gorrie, J. (1851). Improved Process for the Artificial Production of Ice. US8080A.

Guthrie, K. (2014). Solar Heating and Cooling Programme Strategic Plan 20142018. Available at https://www.nachhaltigwirtschaften.at/resources/iea_pdf/ iea_shc_strategic_plan_2014_2018.pdf.

Haider, K., and Anis, K. (2015). Heat Wave Death Toll Rises to 2,000 in Pakistan's Financial Hub. Available at: https://www.bloomberg.com/news/articles/201506-24/heat-wave-death-toll-rises-to-2-000-in-pakistan-s-financial-hub.

Halimic, E., Ross, D., Agnew, B., Anderson, A., and Potts, I. (2003). A Comparison of the Operating Performance of Alternative Refrigerants. Appl. Therm. Eng. 23, 1441-1451. doi:10.1016/s1359-4311(03)00081-4

Hassan, H. Z., and Mohamad, A. A. (2012a). A Review on Solar Cold Production through Absorption Technology. Renew. Sustainable Energ. Rev. 16, 5331-5348. doi:10.1016/j.rser.2012.04.049

Hassan, H. Z., and Mohamad, A. A. (2012b). A Review on Solar Cold Production through Absorption Technology. Renew. Sustainable Energ. Rev. 16, 5331-5348. doi:10.1016/j.rser.2012.04.049

Heath, E. A. (2017). Amendment to the Montreal Protocol on Substances that Deplete the Ozone Layer (Kigali Amendment). Int. Leg. Mater. 56, 193-205. doi:10.1017/ilm.2016.2

Huang, B. J., Yen, C. W., Wu, J. H., Liu, J. H., Hsu, H. Y., Petrenko, V. O., et al. (2010). Optimal Control and Performance Test of Solar-Assisted Cooling System. Appl. Therm. Eng. 30, 2243-2252. doi:10.1016/j.applthermaleng.2010.06.004

Hussain, F., Ashfaq Ahmad, M., Badshah, S., Raza, R., Ajmal Khan, M., Mumtaz, S., et al. (2019). A Modeling Approach for Low-Temperature SOFC-Based Microcombined Heat and Power Systems. Int. J. Mod. Phys. B. 33, 1950001. doi:10.1142/S0217979219500012

IEA (2019). Global Energy and CO2 Status Report. Available at: https://www.iea. org/geco/ (Accessed April 8, 2019).

IEA (2020). Global Energy Review 2019 - Analysis - IEA. Available at: https:// www.iea.org/reports/global-energy-review-2019 (Accessed December 18, 2020). 
Izquierdo, M., Venegas, M., Rodríguez, P., and Lecuona, A. (2004). Crystallization as a Limit to Develop Solar Air-Cooled LiBr-H2o Absorption Systems Using Low-Grade Heat. Solar Energ. Mater. Solar Cell. 81, 205-216. doi:10.1016/ j.solmat.2003.11.002

Jakob, U., Eicker, U., Schneider, D., Taki, A. H., and Cook, M. J. (2008). Simulation and Experimental Investigation into Diffusion Absorption Cooling Machines for Air-Conditioning Applications. Appl. Therm. Eng. 28, 1138-1150. doi:10.1016/j.applthermaleng.2007.08.007

Jia, S. (2009). Evaluation of HCFC Alternative Refrigerants. Available at https://ec. europa.eu/clima/sites/clima/files/docs/0007/heatcraft_evaluation_hcf_alternative_ refrigerants_en.pdf.

Karakaya, E., Nuur, C., and Hidalgo, A. (2016). Business Model challenge: Lessons from a Local Solar Company. Renew. Energ. 85, 1026-1035. doi:10.1016/ j.renene.2015.07.069

Karakaya, E., Nuur, C., and Hidalgo, A. (2014). Business Model challenge: Learnings from a Local Solar Company in Germany, in 1st Annual European Doctorate in Industrial Management Conference. 23.

Khalil, H. B., and Zaidi, S. J. H. (2014). Energy Crisis and Potential of Solar Energy in Pakistan. Renew. Sustainable Energ. Rev. 31, 194-201. doi:10.1016/ j.rser.2013.11.023

Khaliq, A. (2017). Energetic and Exergetic Performance Investigation of a Solar Based Integrated System for Cogeneration of Power and Cooling. Appl. Therm. Eng. 112, 1305-1316. doi:10.1016/j.applthermaleng.2016.10.127

Khan, B. H. (2006). Non-conventional Energy Resources 2nd Edn. New Dehli, India: Tata McGraw-Hill Education Private Lmtd.

Khan, N., Dilshad, S., Khalid, R., Kalair, A. R., and Abas, N. (2019). Review of Energy Storage and Transportation of Energy. Energy Storage. 1, e49. doi:10.1002/est2.49

Leisen, R., Steffen, B., and Weber, C. (2019). Regulatory Risk and the Resilience of New Sustainable Business Models in the Energy Sector. J. Clean. Prod. 219, 865-878. doi:10.1016/j.jclepro.2019.01.330

Li, C., and Shen, B. (2019). Accelerating Renewable Energy Electrification and Rural Economic Development with an Innovative Business Model: A Case Study in China. Energy Policy. 127, 280-286. doi:10.1016/ j.enpol.2018.12.009

Li, X., Chalvatzis, K. J., Stephanides, P., Papapostolou, C., Kondyli, E., Kaldellis, K., et al. (2019a). Bringing Innovation to Market: Business Models for Battery Storage. Energ. Proced. 159, 327-332. doi:10.1016/j.egypro.2019.01.007

Li, Z., Ma, L., Li, Z., and Ni, W. (2019b). Multi-energy Cooperative Utilization Business Models: A Case Study of the Solar-Heat Pump Water Heater. Renew. Sustainable Energ. Rev. 108, 392-397. doi:10.1016/j.rser.2019.04.015

Mansoor, H. (2015). Heatstroke Leaves Another 26 Dead in Sindh. Available at: https://www.dawn.com/news/1191234/heatstroke-leaves-another-26-dead-insindh. doi:10.1063/1.4915055

Mehta, J. R., and Rane, M. V. (2013). Liquid Desiccant Based Solar Air Conditioning System with Novel Evacuated Tube Collector as Regenerator. Proced. Eng. 51, 688-693. doi:10.1016/j.proeng.2013.01.098

Molina, M. J., and Rowland, F. S. (1974). Stratospheric Sink for Chlorofluoromethanes: Chlorine Atom-Catalysed Destruction of Ozone. Nature. 249, 810-812. doi:10.1038/249810a0

Mukhtar, I. (2019). Taxes on Solar, Wind Power Equipment May Be Waived to Boost Production. Available at. https://www.dawn.com/news/1460680.

Murphy, P., and Secretariat, S. H. C. (2011). IEA Solar Heating \& Cooling Programme. 2013 Annual Report. Available at https://www. nachhaltigwirtschaften.at/resources/iea_pdf/reports/iea_shc_annual_report_ 2013.pdf.

Nation (2017). Nation. Heatwave Continues in Larkana 21 April 2017. Available at: https://nation.com.pk/21-Apr-2017/heatwave-continues-in-larkana (Accessed March 1, 2019).

Neyer, D., Ostheimer, M., Mugnier, D., and White, S. (2018). 10 Key Principles for Successful Solar Air Conditioning Design - A Compendium of IEA SHC Task 48 Experiences. Solar Energy 172, 78-89. doi:10.1016/j.solener.2018.03.086

Niaz, Y., and Zhou, J. T. (2014). A Study of Environmental Issues and Air Pollution Control Strategies in Faisalabad, Pakistan Using Geographical Information System (GIS). Adv. Mater. Res. 864-867, 1293-1297. doi:10.4324/ 9781315850801

Niu, X.-D., Yamaguchi, H., Zhang, X.-R., Iwamoto, Y., and Hashitani, N. (2011). Experimental Study of Heat Transfer Characteristics of Supercritical CO2 Fluid in Collectors of Solar Rankine Cycle System. Appl. Therm. Eng. 31, 1279-1285. doi:10.1016/j.applthermaleng.2010.12.034

Osterwalder, A., and Pigneur, Y. (2010). A Handbook for Visionaries, Game Changers, and Challengers Striving to Defy Outmoded Business Models and Design Tomorrow' S Enterprises. Amsterdam, Netherlands: John Wiley \& Sons. doi:10.1523/JNEUROSCI.0307-10.2010

Osterwalder, A., Pigneur, Y., Bernarda, G., and Smith, A. (2014). Value Proposition Design: How to Create Products and Services Customers Want. Hoboken, NJ, United States: John Wiley \& Sons 2.

Pakistan Today (2017). Severe Heatwave Engulfs Most Parts of Sindh. Available at: https://www.pakistantoday.com.pk/2017/03/29/severe-heatwave-engulfs-mostparts-of-sindh/ (Accessed May 2, 2019).

Pakistan Today (2018). Electricity Generation Remains 22,700MW against Demand of 23,055: Power Division. 2018. Available at: https://www. pakistantoday.com.pk/2018/06/27/electricity-generation-remains-22700mwagainst-demand-of-23055-power-division/ (Accessed November 6, 2018).

Pakistan Today (2019). Karachi to Face Heatwave from May 1-3. 1 May 2019. Available at: https://www.pakistantoday.com.pk/2019/04/27/met-officecautions-karachi-of-likely-heat-wave-from-may-1-3/ (Accessed May 1, 2019).

Park, Y. M., and Sonntag, R. E. (1990). Thermodynamic Properties of AmmoniaWater Mixtures: a Generalized Equation-Of-State Approach. Conf. Procedding By ASHRAE. 96, 150-159.

Pátek, J., and Klomfar, J. (1995). Simple Functions for Fast Calculations of Selected Thermodynamic Properties of the Ammonia-Water System. Int. J. Refrigeration. 18, 228-234. doi:10.1016/0140-7007(95)00006-w

PCRET (2006). Pakistan Council of Renewable Energy Technologies: Profile 2006. 28.

PCRET (2018). Success Story. Pakistan Council of Renewable Energy Technologies (PCRET). Islamabad: Pakistan, 2018. Available at: http://www.pcret.gov.pk/ News.html.

Perkins, J. (1834). Apparatus for Producing Ice and Cooling Fluids. UK Patent 6662.

Pongtornkulpanich, A., Thepa, S., Amornkitbamrung, M., and Butcher, C. (2008). Experience with Fully Operational Solar-Driven 10-ton LiBr/H2O Single-Effect Absorption Cooling System in Thailand. Renew. Energ. 33, 943-949. doi:10.1016/j.renene.2007.09.022

Praene, J. P., Marc, O., Lucas, F., and Miranville, F. (2011). Simulation and Experimental Investigation of Solar Absorption Cooling System in Reunion Island. Appl. Energ. 88, 831-839. doi:10.1016/ j.apenergy.2010.09.016

Raza Kalair, A., Abas, N., Seyedmahmoudian, M., Stojcevski, A., and Dilshad, S. (2021). Performance Assessment of Solar Water Heating System Using CO2 under Various Climate Conditions. Energ. Convers. Management. 236, 114061. doi:10.1016/j.enconman.2021.114061

Riaz, R., and Hamid, K. (2018). Existing Smog in Lahore, Pakistan: An Alarming Public Health Concern. Cureus. 10, e2111. doi:10.7759/cureus.2111

Sarkar, J. (2015). Review and Future Trends of Supercritical CO2 Rankine Cycle for Low-Grade Heat Conversion. Renew. Sustainable Energ. Rev. 48, 434-451. doi:10.1016/j.rser.2015.04.039

Shaikh, P. H., Shaikh, F., and Mirani, M. (2013). Solar Energy: Topographical Asset for Pakistan. Appl. Sol. Energ. 49, 49-53. doi:10.3103/ s0003701x1301012x

Shamshad, K. M. (1998). Solar Insolation over Pakistan. Taiyo Enerugi (Journal Jpn. Sol. Energ. Soc. 24, 30

Sheikh, M. A. (2010). Energy and Renewable Energy Scenario of Pakistan. Renew. Sustainable Energ. Rev. 14, 354-363. doi:10.1016/j.rser.2009.07.037

Sivak, M. (2009). Potential Energy Demand for Cooling in the 50 Largest Metropolitan Areas of the World: Implications for Developing Countries. Energy Policy. 37, 1382-1384. doi:10.1016/j.enpol.2008.11.031

Stolarski, R. S., and Cicerone, R. J. (1974). Stratospheric Chlorine: a Possible Sink for Ozone. Can. J. Chem. 52, 1610-1615. doi:10.1139/v74-233

Strategyzer, A. G. (2018a). The Value Proposition Canvas. Available at: https:// strategyzer.com/canvas/value-proposition-canvas.

Strategyzer, A. G. (2018b). The Business Model Canvas. Available at: https:// strategyzer.com/canvas/business-model-canvas.

Tans, P, K. R. (2020). NOAA/ESRL. Trends in Atmospheric Carbon Dioxide Recent Daily Average Mauna Loa CO2. Available at: https://www.esrl.noaa.gov/ $\mathrm{gmd} / \mathrm{ccgg} /$ trends/monthly.html. 
Teece, D. J. (1986). Profiting from Technological Innovation: Implications for Integration, Collaboration, Licensing and Public Policy. Res. Pol. 15, 285-305. doi:10.1016/0048-7333(86)90027-2

Teece, D. J. (2006). Reflections on "Profiting from Innovation". Res. Pol. 35, 1131-1146. doi:10.1016/j.respol.2006.09.009

Teece, D. J. (2018). Business Models and Dynamic Capabilities. Long Range Plann. 51, 40-49. doi:10.1016/j.lrp.2017.06.007

Tierney, M. J. (2007). Options for Solar-Assisted Refrigeration-Trough Collectors and Double-Effect Chillers. Renew. Energ. 32, 183-199. doi:10.1016/j.renene.2006.01.018

Toro-Jarrín, M. A., Ponce-Jaramillo, I. E., and Güemes-Castorena, D. (2016). Methodology for the of Building Process Integration of Business Model Canvas and Technological Roadmap. Technol. Forecast. Soc. Change. 110, 213-225. doi:10.1016/j.techfore.2016.01.009

Ulfat, I., Javed, F., Abbasi, F. A., Kanwal, F., Usman, A., Jahangir, M., et al. (2012). Estimation of Solar Energy Potential for Islamabad, Pakistan. Terragreen 2012: Clean. Energ. Solutions Sustainable Environ. (Cesse). 18, 1496-1500. doi:10.1016/ j.egypro.2012.05.166

United Nations (1997). The Montreal Protocol on Substances that Deplete the Ozone Layer Chapter XXVII 2.a. Available at https://treaties.un.org/Pages/ ViewDetails.aspx?src=TREATY\&mtdsg_no=XXVII-2-a\&chapter=27\&clang=_en.

United Nations (1998). Kyoto Protocol to the United Nations Dramework Convention on Climate Change. 2019. Available at: http://unfccc.int/ resource/docs/convkp/kpeng.pdf (Accessed May 5, 2019).

United Nations (2005). Ratification Status of Pakistan. 2019. Available at: https:// unfccc.int/node/61134 (Accessed October 24, 2019).

United Nations (2015). Paris Agreement United Nations Framework Convention on Climate Change. Paris, Fr.

United Nations (2019). Institutional Strengthening Project for the Implementation of Montreal Protocol - Phase IX. 2019. Available at: https://nation.com.pk/14-Jun2016/pakistan-committed-to-fulfill-its-obligation-under-montreal-protocol-zahid-hamid (Accessed October 24, 2019).

Van Der Pijl, P., Lokitz, J., and Solomon, L. K. (2016a). Design a Better Business: New Tools, Skills, and Mindset for Strategy and Innovation. John Wiley \& Sons. doi:10.1002/9781119272144

Van Der Pijl, P., Solomon, L. K., and Lokitz, J. (2016b). How to Design a Better Business. Hoboken, NJ. USA: John Wiley \& Sons. doi:10.1002/9781119272144

Van Norman, G. A., and Eisenkot, R. (2017). Technology Transfer: from the Research Bench to Commercialization: Part 1: Intellectual Property Rights-Basics of Patents and Copyrights. JACC Basic Transl. Sci. 2, 85-97.
Whatprice (2020a). Jasco CST-110 110kVa Cummins Engine Generator Price in Pakistan - Self Service Online Supermarket. Available at: http://www.whatprice. com.pk/index.php/home-electrical/power-backup/heavy-generators/jasco/ 10052-jasco-cst-110-110kva-cummins-engine-generator (Accessed May 12, 2020).

Whatprice (2020b). Jasco CST-275 275kVa Cummins Engine Generator Price in Pakistan - Self Service Online Supermarket. Available at: http://www.whatprice. com.pk/index.php/home-electrical/power-backup/heavy-generators/jasco/ 10054-jasco-cst-275-275kva-cummins-engine-generator (Accessed May 12, 2020).

World Energy Outlook 2020 - Analysis - IEA (2020). WEO. Available at: https://www.iea.org/reports/world-energy-outlook-2020 (Accessed May 12, 2020).

Yamaguchi, H., Zhang, X. R., Fujima, K., Enomoto, M., and Sawada, N. (2006). Solar Energy Powered Rankine Cycle Using Supercritical CO2. Appl. Therm. Eng. 26, 2345-2354. doi:10.1016/j.applthermaleng.2006.02.029

Zhang, C., and Yan, J. (2014). Business Model Innovation on the Photovoltaic Water Pumping Systems for Grassland and farmland Conservation in China. Energ. Proced. 61, 1483-1486. doi:10.1016/j.egypro.2014.12.152

Zhang, S. (2016). Innovative Business Models and Financing Mechanisms for Distributed Solar PV (DSPV) Deployment in China. Energy Policy. 95, 458-467. doi:10.1016/j.enpol.2016.01.022

Zhang, X.-R., Yamaguchi, H., and Uneno, D. (2007). Experimental Study on the Performance of Solar Rankine System Using Supercritical CO2. Renew. Energ. 32, 2617-2628. doi:10.1016/j.renene.2007.01.003

Conflict of Interest: KK was employed by Brightcell Energy.

The remaining authors declare that the research was conducted in the absence of any commercial or financial relationships that could be construed as a potential conflict of interest.

Copyright (c) 2021 Kalair, Dilshad, Abas, Seyedmahmoudian, Stojcevski and Koh. This is an open-access article distributed under the terms of the Creative Commons Attribution License (CC BY). The use, distribution or reproduction in other forums is permitted, provided the original author(s) and the copyright owner(s) are credited and that the original publication in this journal is cited, in accordance with accepted academic practice. No use, distribution or reproduction is permitted which does not comply with these terms. 